Water Resources Research

\author{
RESEARCH ARTICLE \\ 10.1029/2019WR025210 \\ Key Points: \\ - Dam-induced bank storage fluid and \\ solute exchange was simulated for a \\ $100-\mathrm{km}$ synthetic river subjected to \\ realistic dam release signals \\ - A large fraction of initial exchange \\ near a dam can occur well beyond \\ $100 \mathrm{~km}$ downstream \\ - Positive, neutral, or negative \\ groundwater gradients along the \\ reach substantially change the \\ quantity of bank storage exchange
}

Supporting Information:

- Supporting Information S1

- Data Set S1

- Table S1

Correspondence to:

S. B. Ferencz,

stephenferencz@gmail.com

Citation:

Ferencz, S. B., Cardenas, M. B., \& Neilson, B. T. (2019). Analysis of the effects of dam release properties and ambient groundwater flow on surface water-groundwater exchange over a 100-km-long reach. Water Resources Research, 55. https://doi.org/10.1029/ 2019WR025210

Received 21 MAR 2019 Accepted 8 SEP 2019

Accepted article online 14 Sept 2019

\section{Analysis of the Effects of Dam Release Properties and Ambient Groundwater Flow on Surface Water-Groundwater Exchange Over a 100-km-Long Reach}

\author{
Stephen B. Ferencz ${ }^{1}$ iD, M. Bayani Cardenas ${ }^{1}$ iD, and Bethany T. Neilson ${ }^{2}$ iD \\ ${ }^{1}$ Department of Geological Sciences, The University of Texas at Austin, Austin, TX, USA, ${ }^{2}$ Civil and Environmental \\ Engineering, Utah Water Research Laboratory, Utah State University, Logan, UT, USA
}

\begin{abstract}
Hydroelectric dams often create highly dynamic downstream flows that promote surface water-groundwater (SW-GW) interactions including bank storage, the temporary storage of river water in the riverbank. Previous research on SW-GW exchanges in dammed rivers has primarily been at single study sites, which has limited the understanding of how these exchanges evolve as dam releases travel downstream. This study evaluates how dam releases affect SW-GW exchange continuously over a 100-km distance. This is accomplished by longitudinally routing water releases through a synthetic river and modeling bed and bank fluid and solute exchange across transverse transects spaced along the reach. Peak and square dam release hydrograph shapes with three magnitudes $(0.5,1.0$, and $1.5 \mathrm{~m})$ were considered. The effect of four ambient groundwater flow conditions (very slightly losing, neutral, and two gaining from the perspective of the river) was evaluated for each dam release scenario. Both types of dam release shapes cause SW-GW interaction over the entire 100-km distance, and our results show that square type releases cause bank storage exchange well beyond this distance. Strongly gaining conditions reduce the amount of exchange and allow flushing of river-sourced solute out of the bank after the dam pulse has passed. Both neutral and losing conditions have larger fluid and solute flux into the bank and limit the amount of solute that returns to the river. Our results support that river corridors downstream of dams have increased river-aquifer connectivity and that this enhanced connectivity can extend at least $100 \mathrm{~km}$ downstream.
\end{abstract}

Plain Language Summary Rivers downstream from dams that generate hydroelectric power can experience frequent water level changes as discharge from the dam is increased or decreased to meet electricity demands. Dam releases can be of similar size to storm runoff events caused by precipitation, but they often occur with more regularity. A large body of research indicates that the exchange of surface water and groundwater (SW-GW) can play an important role in the ecology, nutrient cycling, and overall ecosystem health of river environments. This study uses computer simulations to evaluate how dam releases affect SW-GW interactions. Instead of collecting observations at a handful of field locations as typically done, our approach enabled us to test how a wide range of dam release properties affect SW-GW interactions continuously over a long distance downstream. Our results show that depending on the type and size of hydropower release and the groundwater conditions, the volume of exchange between the river and groundwater can range from 1 to almost 200 Olympic swimming pools over a $100 \mathrm{~km}$ length of river. Our findings can help predict where hydropower operations are more likely to cause SW-GW exchange and thus help management of river corridors and guide future studies in dammed rivers.

\section{Introduction}

Dam releases cause river stage fluctuations with timescales varying from hourly to seasonal and with magnitudes ranging from centimeter oscillations to multiple meters. Dam-induced stage fluctuations facilitate the movement of water and solutes between rivers and their adjoining hyporheic and riparian zones and aquifers, often with important consequences for biogeochemical cycling of ecologically important compounds such as nitrate or dissolved organic carbon (Harvey \& Gooseff, 2015). As river stage increases, water can flow from the river into the surrounding sediments, filling the unsaturated zone and displacing ambient hyporheic water or groundwater. As the stage subsides, water can flow back toward the river.
(C)2019. American Geophysical Union. All Rights Reserved. 


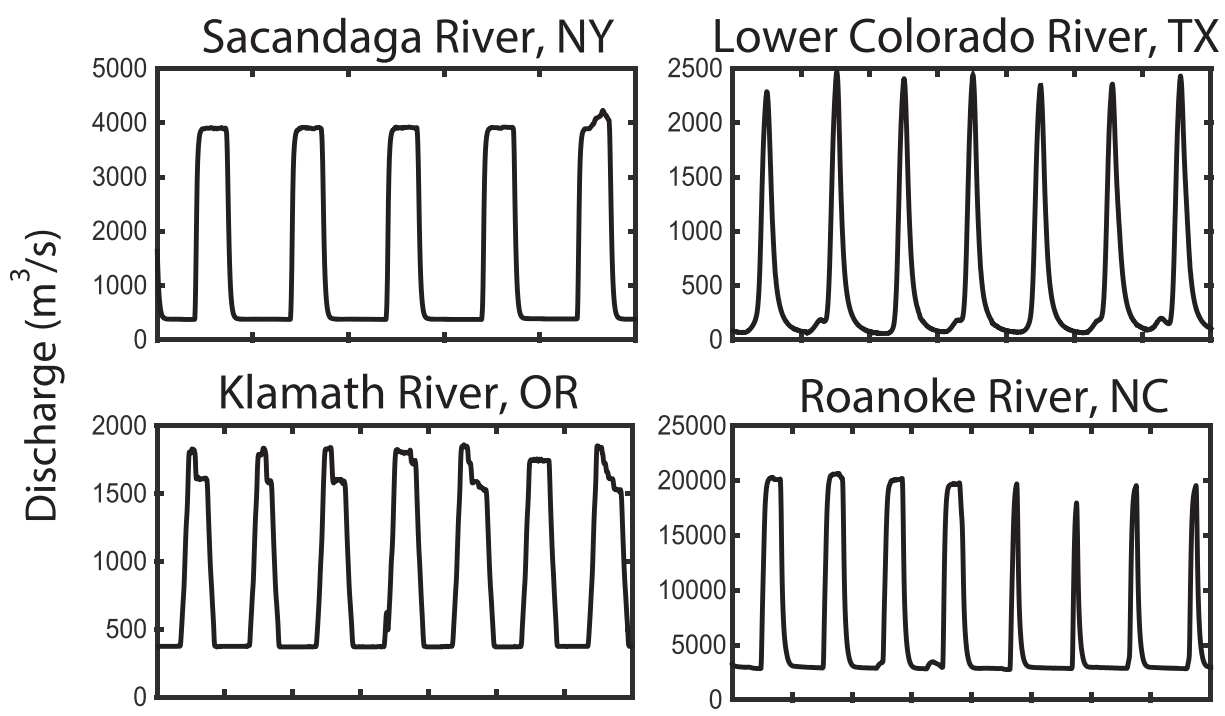

Figure 1. Examples of square and peak dam releases from four regulated rivers in the United States. The $x$-axis ticks are days.

The process of filling and emptying of the bank and near-bank riverbed sediments that occurs during stage fluctuations is called bank storage exchange (BSE). BSE facilitates "hydrologic exchange flow" defined by Harvey and Gooseff (2015) as the lateral and vertical exchanges of water, materials (solids and solutes), and energy between rivers and their surrounding subsurface waters. Throughout this paper we use BSE to describe the hydrostatically driven movement of mass (fluid and solute) between rivers and their adjoining sediments, and we use the term BSE-zone to describe the area of the bank and below the riverbed that receives river water during river fluctuations. Examples of important processes that BSE influences include contaminant and nutrient dynamics (Gu et al., 2012; Shuai et al., 2017; Yim \& Mohsen, 1992), sustaining flows during dry periods (Kondolf et al., 1987; Rhodes et al., 2017), and attenuating flood pulses (Hunt, 1990; Pinder \& Sauer, 1971). Interest in studying BSE has grown with the recognition of the important ecosystem services surface water-groundwater (SW-GW) interactions provide for nutrient cycling and the overall health and functioning of aquatic environments (Brunke \& Gonser, 1997; Harvey \& Gooseff, 2015).

Research on BSE processes is a long-studied topic in hydrology, and many of the foundational conceptualizations were formulated before the advent of powerful computing now common in the discipline (Cooper \& Rorabaugh, 1963; Moench et al., 1974; Newcomb \& Brown, 1961; Rorabaugh, 1963). Recently there has been a resurgence of interest in evaluating and understanding BSE processes. An area of focus for recent research on BSE is in highly dynamic dam-regulated rivers (Boutt \& Flemming, 2009; Sawyer et al., 2009; Shuai et al., 2017; Song et al., 2018; Yellen \& Boutt, 2015). The frequency of river fluctuations that cause BSE events is often much higher in dam-regulated rivers than in natural rivers (Bevelhimer et al., 2015). High frequencies of stage fluctuations are common downstream of hydropower facilities where stage fluctuations occur on daily or even sub-daily timescales to meet power demands (McManamay et al., 2016). The hydroelectric management practice of abruptly switching from low flow to high flow to meet energy demands is termed "hydropeaking." Four examples of hydropeaked rivers with daily flow/stage changes controlled by dam operations are shown in Figure 1. Although these rivers are distributed across a wide variety of climates (New York, North Carolina, Oregon, and Texas in the United States), their hydrographs are not the result of meteorological events but are instead due to daily dam releases.

The increased regularity of BSE events in dam-regulated rivers creates unique river environments characterized by frequent stage oscillations. The regions where rivers experience high-frequency dam-induced flooding events can extend over tens to even hundreds of kilometers downstream from dams (Kennedy et al., 2016). In the United States there are hundreds of dams that are hydropeaked (McManamay et al., 2016), and worldwide it has been estimated that over half of Earth's river systems have been altered for 
electricity generation (Rosenberg et al., 2000). Additionally, it is likely that more hydropower plants will be brought online in the 21st century because hydropower is viewed as a green, low-cost source of energy production that has a smaller carbon footprint than energy production via conventional hydrocarbon power plants (Jones, 2014). Developing a complete understanding of hydrological processes in dam-regulated rivers is essential to understanding the ecosystem and water resource implications of dam operations. One component of building a comprehensive picture of how dam operations affect river ecosystems is understanding their effect on BSE.

The vast majority of the research on BSE has been focused on understanding the mechanistic controls on BSE processes at the plot transect scale, typically a few to tens of meters. Field and modeling studies at the transect scale typically study BSE processes at an individual 2-D transect oriented perpendicular to the channel (Chen \& Chen, 2003; Doble et al., 2012; Koussis et al., 2007; Rorabaugh, 1963; Squillace, 1996). Few studies have looked at spatial and temporal BSE dynamics from a longitudinal perspective (Liang et al., 2018; Pinder \& Sauer, 1971; Xie et al., 2016). Each of these studies evaluated the effect that a flood wave moving down a river corridor has on the spatiotemporal BSE. However, in each study, the flood waves modeled were based on natural flood hydrographs that are not representative of typical hydropeaking releases (Figure 1).

As a dam release propagates downstream, the flood wave is attenuated causing a decrease in wave height and an increase in wavelength. Liang et al. (2018) conducted a modeling study that examined how changes in the shape of a flood wave create changes in rates of BSE flux. Their work supports the idea that as the shape of dam-induced flood wave changes as it travels downstream, so too does the resulting exchange rates and overall quantity of BSE. Therefore, to understand the cumulative importance of BSE in dam-regulated rivers, it is necessary to use a longitudinal approach that accounts for the longitudinal changes in SW-GW exchanges via BSE that result from the attenuation of realistic dam-induced flood waves.

To systematically quantify the effects of dam operations on SW-GW exchanges with both high resolution and over large distances, we used numerical models to test the effect of flood waves from synthetic dam releases on BSE over a distance of $100 \mathrm{~km}$. We modeled two dam release flood shapes that are common in hydropeaked rivers and considered three flood wave sizes, ranging from 0.5 to $1.5 \mathrm{~m}$ in amplitude. Our approach couples propagating realistic dam releases along a 100-km idealized river using the U.S. Army Corps of Engineers surface water routing model HEC-RAS and then simulating the resulting BSE using a finite element model of 2-D variably saturated subsurface flow implemented in COMSOL Multiphysics, a commercial finite element modeling software. Our models also consider the effect of ambient groundwater flow conditions to explore the interaction of the dam releases with losing, neutral, and gaining groundwater conditions in the riverbank. In addition to testing a range of ambient groundwater flow conditions, we also varied hydraulic conductivity to test how this key parameter influences longitudinal BSE. We use both volume of fluid exchange and total area of the bed and the bank that river solute infiltrates as metrics for comparing the amount of SW-GW interaction resulting from the different model scenarios. While the models include the bed of the river, we collectively refer to the exchange as BSE since it is dominated by bank rather than bed exchange.

\section{Methods}

\subsection{Simulated Dam Signals and Experimental River Properties}

Dam signals reflective of realistic conditions for a river downstream of a hydropeaking facility were used for this study. We considered two dam release shapes that are present in hydropeaked rivers (Figure 1). The first shape looks similar to a square wave where discharge (power generation) ramps up to and is held at a sustained level for several hours. The other type is an abrupt peak shape that ramps up to a maximum height and immediately declines. The square releases were modeled with sustained maximum discharge held for $8 \mathrm{hr}$, while the peak releases only had a maximum discharge for $15 \mathrm{~min}$. We evaluated three sizes of hydropeaking releases whose discharge resulted in stage changes immediately below the dam of $0.5,1$, and $1.5 \mathrm{~m}$. These are common amplitudes for hydropeaking releases in rivers in the United States.

We used a simple, idealized channel geometry and fixed channel properties (slope, width, and roughness) for our synthetic river to constrain the number of variables under consideration. This allowed us to isolate and test the effects of (1) different dam release scenarios and (2) ambient groundwater conditions on BSE. Similar simplifying assumptions about channel dimensions and properties have been made in other longitudinal 
BSE studies (Liang et al., 2018; Pinder \& Sauer, 1971; Xie et al., 2016). The experimental river was given a constant width of $80 \mathrm{~m}$ and a slope of 0.0005 . The slope is representative of a higher order, lowland river such as the Brazos, Nueces, and Lower Colorado rivers in Texas; other familiar examples include the Missouri and Arkansas Rivers (Larkin \& Sharp, 1992). These values are almost identical to the average width and slope of the hydropeaked Lower Colorado River, Texas, USA, which has been the focus of numerous dam-induced SW-GW exchange studies over the past decade (Gerecht et al., 2011; Sawyer et al., 2009; Watson et al., 2018).

While not the focus of this study, to demonstrate how changes in roughness and channel slope influence longitudinal patterns in BSE, we ran a small number of models in which two other roughness values and one other channel slope were considered. The two additional roughness values spanned the extremes expected for a river, ranging from a minimum value of 0.025 to a maximum value of 0.05 . The other channel slope we modeled was twice as steep as the one used for this study (0.001 vs. 0.0005$)$. Because a comprehensive assessment of channel roughness and slope is outside the scope of this study, for these scenarios we only tested a 1-m peak release and only quantified longitudinal BSE using volumetric inflow into the bank.

\subsection{Flow and Transport Model Description}

\subsubsection{Governing Equations}

The 1-D surface water routing was modeled using HEC-RAS version 4.1.0 (U.S. Army Corps of Engineers, HEC-RAS, Hydrologic Engineering Center), which solves the conservation of mass and momentum equations for a dynamic wave. The transient response of river stage to a dam release is represented by the dynamic form of the 1-D shallow water equations. The coupled mass (equation (1)) and momentum (equation (2)) equations that govern transient surface water flow were solved numerically using a four-point implicit finite difference approach with a weighting factor $\Theta=1$, which has been shown to be unconditionally stable (US Army Corps of Engineers Hydraulic Engineering Center, 2016). The equations are as follows:

$$
\begin{gathered}
\frac{\partial A}{\partial t}+\frac{\partial(A u)}{\partial x}=0 \\
\frac{\partial u}{\partial t}+u \frac{\partial u}{\partial x}+g \frac{\partial \zeta}{\partial x}=-\frac{P \tau}{A \rho},
\end{gathered}
$$

where $A$ is channel cross-sectional area $\left[\mathrm{L}^{2}\right], u$ is flow velocity $\left[\mathrm{LT}^{-}\right], x$ is the longitudinal downstream direction $[\mathrm{L}], g$ is gravitational acceleration $\left[\mathrm{LT}^{-2}\right], \zeta$ is the free surface elevation $[\mathrm{L}], P$ is the wetted perimeter of the channel $[\mathrm{L}], \tau$ is the wall sheer stress $\left[\mathrm{MT}^{-2} \mathrm{~L}^{-}\right]$, and $\rho$ is the fluid density $\left[\mathrm{ML}^{-3}\right]$.

The fluid flow and solute transport between the river and aquifer was solved by coupling flow in unsaturated porous media based on Richard's equation (equation (3)) and solute transport based on the advectiondispersion equation (equation (4)). The coupled subsurface flow and transport equations were solved with a segregated solver that evaluated the fluid flow and solute advection-dispersion equations sequentially.

$$
\begin{gathered}
\rho\left(\frac{C_{m}}{\rho g}+S_{e} S\right) \frac{\partial p}{\partial t}+\nabla \cdot \rho\left(-\frac{k_{s}}{\mu} k_{r}(\nabla p+\rho g \nabla z)\right)=Q_{m}, \\
\frac{\partial}{\partial t}(\theta C)=-\nabla \cdot \rho(q C)+\left(D \nabla^{2} C\right),
\end{gathered}
$$

where $p$ is pressure $\left[\mathrm{MT}^{-2} \mathrm{~L}^{-}\right], \rho$ is fluid density $\left[\mathrm{ML}^{-3}\right], C_{m}$ is specific moisture capacity $\left[\mathrm{L}^{-}\right], S_{e}$ is effective saturation [-], $S$ is the storage coefficient $[-], k_{S}$ is the saturated hydraulic permeability $\left[\mathrm{L}^{2}\right], k_{r}$ is the relative permeability dependent on saturation $[-], \mu$ is the dynamic viscosity of the fluid (water) $\left[\mathrm{ML}^{-} \mathrm{T}^{-}\right], z$ is the elevation head $[\mathrm{L}], g$ is gravitational acceleration $\left[\mathrm{LT}^{-2}\right]$, and $Q_{m}$ is a stress source term that accounts for changes in total stress under fluctuating river stage $\left[\mathrm{ML}^{-3} \mathrm{~T}^{-}\right] . C$ is the concentration of the conservative solute $\left[\mathrm{ML}^{-3}\right], \theta$ is the volumetric water content $[-], q$ is the Darcy velocity $\left[\mathrm{LT}^{-}\right]$, and $D\left[\mathrm{~L}^{2} \mathrm{~T}^{-}\right]$is the effective dispersion coefficient which includes the macro-dispersion tensor, defined by dispersivity and pore velocity, plus molecular diffusion.

\subsubsection{Surface Water Model Configuration}

We used a 1-D routing model to simulate the river stage response to different dam release scenarios. The geometry and boundary conditions for the 1-D surface water model were set to a constant channel width of $80 \mathrm{~m}$, slope of 0.0005, Manning's roughness of 0.035, and trapezoidal cross-sectional shape with the bank sloped at 


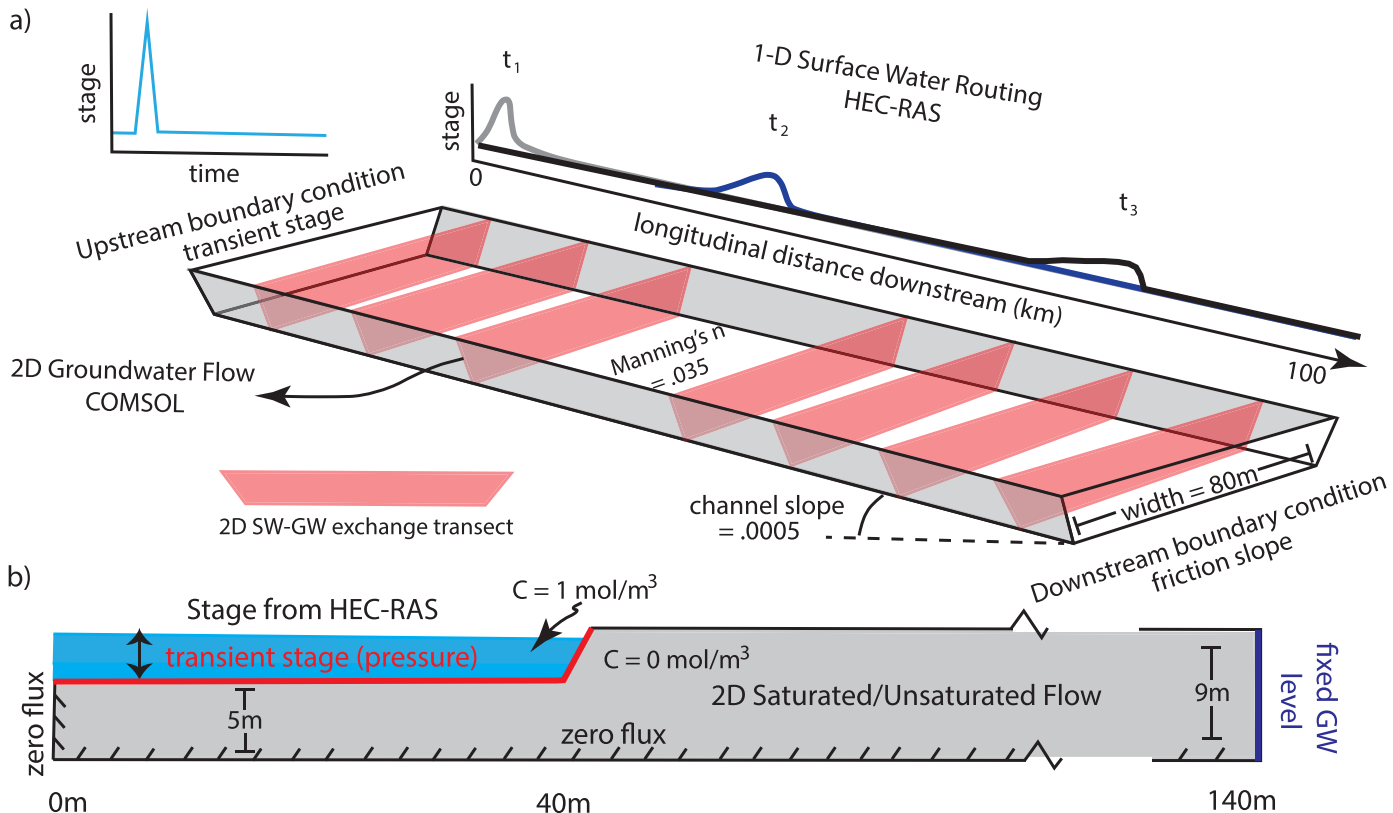

Figure 2. Schematic of the longitudinal-transverse model design for this study. The surface water routing for the dam release was modeled as a 1-D dynamic wave following the 1-D St. Venant Equations and was implemented in U.S. Army Corps HEC-RAS. Time series of river stage response to dam releases were exported from HEC-RAS and used as pressure boundary conditions for 2-D Richard's flow models run in COMSOL Multiphysics.

$70^{\circ}$ (Figure 2a). A small number of additional simulations were conducted to test two other roughness values (0.025 and 0.05) and one other channel slope (0.001). The upstream inflow boundary condition was a transient stage specified for the desired dam release shape and magnitude. The downstream outflow boundary condition was set as a friction slope. To ensure that backwater effects at the downstream end of the model domain did not influence the upstream river stage response, we evaluated the dam release simulations over a 200-km domain of which only the first $100 \mathrm{~km}$ of river stage data was used. The model was evaluated with a grid spacing of $1 \mathrm{~km}$ and time steps of $30 \mathrm{~s}$. Appropriate grid spacing was determined using an equation that relates bank full depth and bed slope (Fread \& Lewis, 1993; US Army Corps of Engineers Hydraulic Engineering Center, 2016). Time series of river stage were exported at the desired transverse groundwater model locations between the dam and $100 \mathrm{~km}$ downstream. The hydrographs generated from the HEC-RAS models were used as the river stage boundary conditions at specific locations for the 2-D subsurface flow models (Figure 2).

\subsubsection{Subsurface Flow and Transport Model Configuration}

The subsurface modeling domain was $140 \mathrm{~m}$ in length (40-m channel and 100-m bank), and the unconfined alluvial aquifer was given a depth of $5 \mathrm{~m}$ beneath the riverbed and $9 \mathrm{~m}$ in the bank (Figure $2 \mathrm{~b}$ ). To reduce the size of the modeling domain, the river transect was modeled as a half width. The aquifer hydraulic properties for the base case were homogenous and isotropic with constant saturated hydraulic conductivity $K$ of $10 \mathrm{~m} /$ day (with $\rho=998 \mathrm{~kg} / \mathrm{m}^{3}$ and $\mu=1.002 \mathrm{mPa} / \mathrm{s}$; this corresponds to $k_{s}=1.2 \times 10^{-11} \mathrm{~m}^{2}$ ) and had a porosity of 0.3 , representative values for medium sand. A small subset of models tested the effect of $K$ on BSE flux and considered two additional $K$ values of 1 and $50 \mathrm{~m} /$ day. The van Genuchten parameters were $10 \mathrm{~m}^{-1}$ for $\alpha$ and 2 for $n$. No flow (zero flux) boundaries were assigned to the aquifer base and at the symmetry boundary at the left-hand side (i.e., the center of the channel). The top boundary of the model was set as a seepage face to realistically capture the filling and draining of the riverbank as the river stage fluctuates. The seepage face was implemented as a mixed boundary using a conditional statement that partitions elements along the top boundary into zero pressure for elements along the seepage face and zero flux for elements that are above the seepage face. Pressure along the top boundary of the flow model was set as a time-varying head boundary parameterized from the river stage hydrographs generated in HEC-RAS. The right boundary (as shown in Figure 2) was set as constant head and was used to control the ambient groundwater gradient-defined as the difference in head between the right-hand boundary and the background river level divided by the 100- 
$m$ width of bank. The lateral extent of the domain was chosen such that the range of stage fluctuations considered would not result in water level fluctuations at the right-hand boundary.

We used a conservative solute as the tracer to track the growth of the BSE-zone under the different dam release scenarios and ambient groundwater configurations. The initial solute concentration in the subsurface transport model was set to $0 \mathrm{~mol} / \mathrm{m}^{3}$. The portion of the top boundary that was at or below the river stage was given an arbitrary constant solute concentration of $1 \mathrm{~mol} / \mathrm{m}^{3}$, representing the conservative solute tracer in the river $\left(\mathrm{C}_{\text {riv }}\right)$. Horizontal dispersivity was set to $1 \mathrm{~m}$, and vertical dispersivity was set at $0.1 \mathrm{~m}(1 / 10$ th of longitudinal). The molecular diffusion coefficient of the conservative solute was set at $10^{-10} \mathrm{~m}^{2} / \mathrm{s}$. In order to solve unsaturated flow and transport under highly transient conditions, we used a small triangular element size (ranging from $0.01 \mathrm{~m}$ along the bank up to $0.3 \mathrm{~m}$ at further distances) and time step size (maximum $100 \mathrm{~s})$ to maintain numerical stability and to minimize numerical dispersion.

\subsection{Ambient Groundwater Condition Scenarios}

In the absence of stage fluctuations, gaining and neutral groundwater conditions limit the exchange of river water with bank. The multiple dam release shapes and sizes that were evaluated and the large longitudinal scale over which we simulated dam-induced BSE limited the number of ambient groundwater conditions that could be considered. We chose to model two different gaining groundwater conditions, one "strongly" gaining with a gradient of +0.015 toward the river and the other "moderately" gaining with a gradient of +0.0075 . The neutral gradient was also included as a baseline comparison and also representative of banks that have very gently sloping water tables (either very weakly gaining or losing). We also examined the effect that transient stage fluctuations would have on the amount of fluid and solute movement from the river into the bank under losing conditions and how this would differ from the background state. Since this was not the primary focus of this study, dam release scenarios were only tested for one value (head gradient $=-0.0075$ ).

\subsection{Hydraulic Conductivity Scenarios}

Hydraulic conductivity is a key control on rates of fluid and solute transport in porous media and thus could be important for longitudinal distribution of BSE fluxes. A priori, it is not apparent how hydraulic conductivity would affect the longitudinal distribution of BSE for a propagating dam release, and this is further complicated if one considers how variations in $K$ interact with different ambient groundwater conditions. To explore the effect of hydraulic conductivity on longitudinal BSE, we evaluated volumetric BSE flux for two additional aquifer $K$ values of 1 and $50 \mathrm{~m}$ /day. For this set of scenarios, we considered 1-m peak and square dam signals with neutral and gaining (0.0075 and 0.015) ambient groundwater conditions.

\subsection{Quantifying Volumetric Flux and Solute Area in the Riverbank}

The two metrics that we used to quantify SW-GW exchange under the different dam release and groundwater flow scenarios are (1) volumetric fluid flux and (2) subsurface area inundated by the river-sourced solute (BSE-zone), which can also be viewed as the hyporheic zone extent.

Volumetric exchange flux is one of the most common metrics quantified in field and modeling studies of BSE. In field studies, volumetric flux is typically inferred from estimating Darcy fluxes based on gradients between water levels in monitoring wells and the height of the river (Sawyer et al., 2009; Welch et al., 2014). Field estimates of volumetric BSE flux are time, labor, and cost intensive, which is why volumetric flux values are more commonly reported in numerical modeling studies of BSE processes (Chen \& Chen, 2003; Doble et al., 2012; Welch et al., 2013). Volumetric flux is important for understanding the influence of short-term (natural or man-made) flood events on longer term chemical composition and water balance between rivers and their alluvial aquifers (McCallum \& Shanafield, 2016). Volumetric flux can also serve as a proxy for the potential for biogeochemical transformations of solutes as shown in Gu et al. (2012).

The size of the BSE-zone was evaluated because it is a controlling factor for the ecological function of riverbanks as hot spots of biogeochemical processing. Because a conservative solute was modeled, the simulation does not capture the formation of redox zones in the bank that exert control over the types of biogeochemical reactions that occur (e.g., Boano et al., 2010; Shuai et al., 2017). However, using a conservative solute provided the computational flexibility to run hundreds of simulations to evaluate controls on BSE at the longitudinal scale of $100 \mathrm{~km}$. Opinions about what percentage of river water chemically constitutes the hyporheic zone vary. A commonly used value is greater than $10 \%$ river water suggested by Triska et al. 


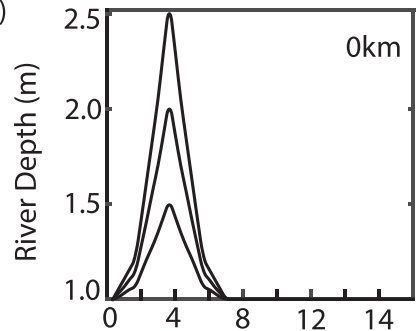

b)

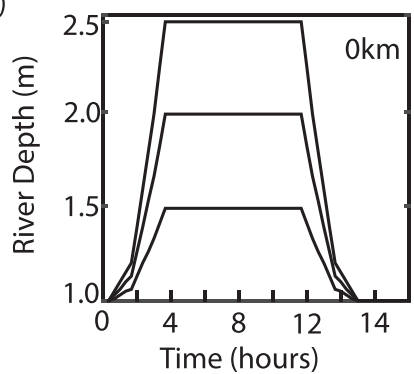

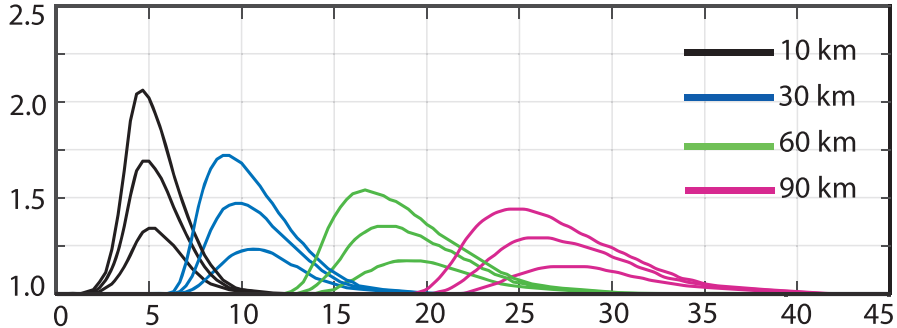

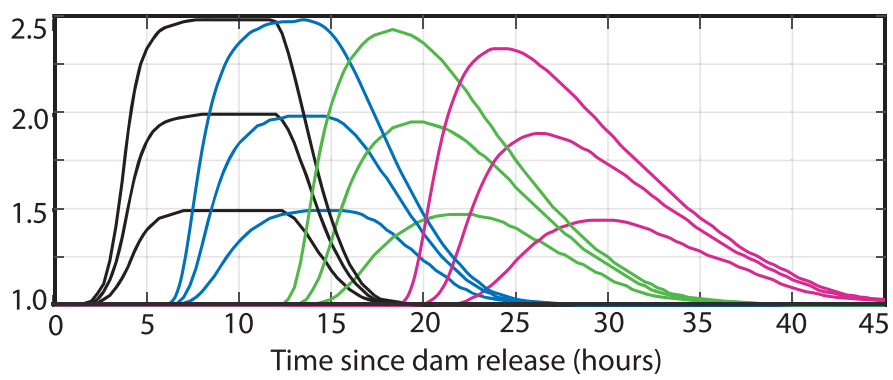

Figure 3. Idealized peak (a) and square (b) dam release signals used for bank storage exchange models, and resulting river depth changes are shown at 10, 30,60, and $90 \mathrm{~km}$ downstream from the dam. Stage hydrographs were used as time-varying head boundary conditions for the bank storage exchange models.

(1989) three decades ago. There also are much looser definitions such as Findlay (1995) who defined the hyporheic zone as the region of the subsurface that contains any percent river water. Both definitions are based on arbitrary values and are not determined by the effects these concentrations would have on hyporheic zone biogeochemical processes. We chose to evaluate solute area for quartiles of river concentration, generating a time series of the area in the bank where the concentration of the pore water (C) is greater than or equal to $25 \%, 50 \%, 75 \%$, or $95 \%$ of the river concentration $\left(\mathrm{C}_{\text {riv }}\right)$. The figures in the main text present the results for the $>25 \%$ river water concentrations $\left(C / C_{\text {riv }}>0.25\right)$. The results for the other three quartiles are presented in Supporting Information, Figures S1-S3.

Time series of boundary fluid flux and subsurface solute area were exported from the subsurface flow simulations every 1,000 s. These results were then used to calculate volumetric BSE flux and changes in the size of the BSE-zone. The total fluid flux was calculated by integrating the net boundary flux across the top boundary (riverbed and bank), and volumetric flux was calculated by integrating the fluid flux rate through time. The solute area was obtained by integrating the area of the model domain containing solute concentrations greater than the specified concentration value.

\section{Results}

\subsection{River Stage Response to Dam Release Scenarios}

The two types of dam release shapes resulted in different longitudinal patterns in river stage fluctuations (Figure 3). A key difference between the peak (Figure 3a) and square releases (Figure 3b) is that the flood wave created by peak releases decays much more rapidly than the square releases. The rapid decay of the peak flood wave compared to the square flood wave is illustrated in Figure 3, which shows time series of river stage at locations of 10, 30, 60, and $90 \mathrm{~km}$ downstream from the dam for the three sizes of dam release $(0.5$, 1.0 , and $1.5 \mathrm{~m}$ ). Comparing the flood waves from the $1.5 \mathrm{-m}$ peak and square releases at $30 \mathrm{~km}$ downstream provides an example of the more rapid attenuation of the peak releases: At this location the $1.5-\mathrm{m}$ peak release has a height of $0.7 \mathrm{~m}$ ( $46 \%$ of initial size) while the square release has a height of $1.45 \mathrm{~m}$ ( $96 \%$ of initial size). Large decay in wave height for the peak releases and small amounts for square releases is consistent across all three dam release sizes. A shared characteristic between the two types of dam releases is that the wavelengths of the flood waves increase as they travel downstream. The attenuation of the peak releases increased the wavelength from 5 to $17 \mathrm{hr}$ while the wavelength of the square releases increased from 11 to $23.5 \mathrm{hr}$. Differences in the hydrographs created by the peak and square releases resulted in characteristic longitudinal distributions of BSE for the two release shapes. 

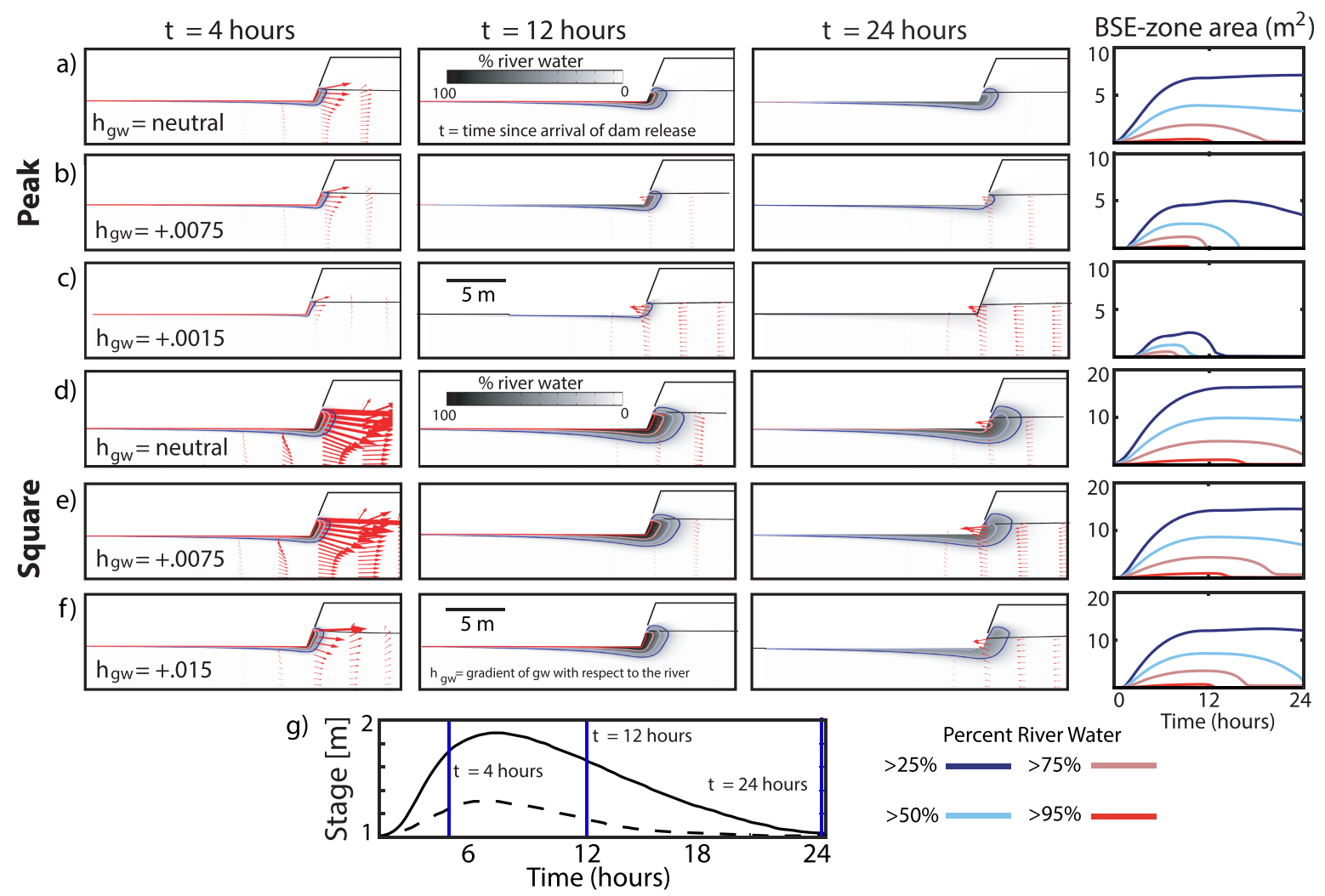

Figure 4. Snapshots of flow field and river-sourced solute concentration in the bank over a 24-hr period at $90 \mathrm{~km}$ downstream resulting from 1-m peak (a-c) and square (d-f) releases. The effect of three different ambient groundwater head ranging from neutral (a and d), +0.0075 (b and e), and +0.015 (c and f). The peak and square hydrographs annotated with each snapshot time are shown in (g) - peak is dashed, and square is solid. The size of the area in the bank that has pore fluid concentrations defined as a percentage of river concentration $(>25 \%,>50 \%,>75 \%$, and $>95 \%$ river water) is shown in the right-most column.

\subsection{Snapshots of Flow Field and Solute Distribution Under Different Dam Release Signals and Ambient Groundwater Gradients}

The 2-D lateral exchange models show that the spatiotemporal response of the flow field and solute distribution in the riverbank to be highly dependent on the dam release type (peak vs. square) and ambient groundwater flow conditions (Figure 4). These snapshots from 1-m peak and square releases at a transect $90 \mathrm{~km}$ downstream of the dam illustrate infiltration during river stage rise and exfiltration as the river stage returns to its original level. The last snapshot is at $24 \mathrm{hr}$ because under repeating daily hydropeaking conditions, a dam release would be arriving and initiating another BSE event. Therefore, the snapshots at $24 \mathrm{hr}$ show the maximum recovery to ambient, pre-dam release conditions.

Similar to the findings of Welch et al. (2013) and Shuai et al. (2017), our simulations showed that a gaining ambient head gradient limits the infiltration of river water and accompanying solute during stage increases (Figures $4 \mathrm{c}$ and $4 \mathrm{f}$ ). Clear differences in the size of the BSE-zone during infiltration are apparent depending on the ambient groundwater head gradient. The ambient groundwater head gradient also controls the exfiltration or return flow of solute back into the river. The effect of ambient groundwater gradients on the capacity to flush solute out of the bank can be seen by comparing the extent of river-borne solute in the riverbank at $t=24 \mathrm{hr}$ for the three ambient head gradients (Figures 4a-4f). The snapshots show that larger groundwater head gradients, and thus more flow toward the river, result in BSE-zone areas with smaller extent and lower solute concentration.

A common feature of all of scenarios is that lateral flow into the bank, not vertical flow into the riverbed, is the primary mechanism of SW-GW exchange during stage fluctuations. This can be seen both in the size of the flow vectors (red arrows), which are scaled to reflect magnitude of fluid velocity, and in the distribution of river-sourced solute (shown in gray scale) in the subsurface (Figure 4). Another important feature shared by all six scenarios is that some amount of solute remains in the bank after $24 \mathrm{hr}$. Under conditions of 


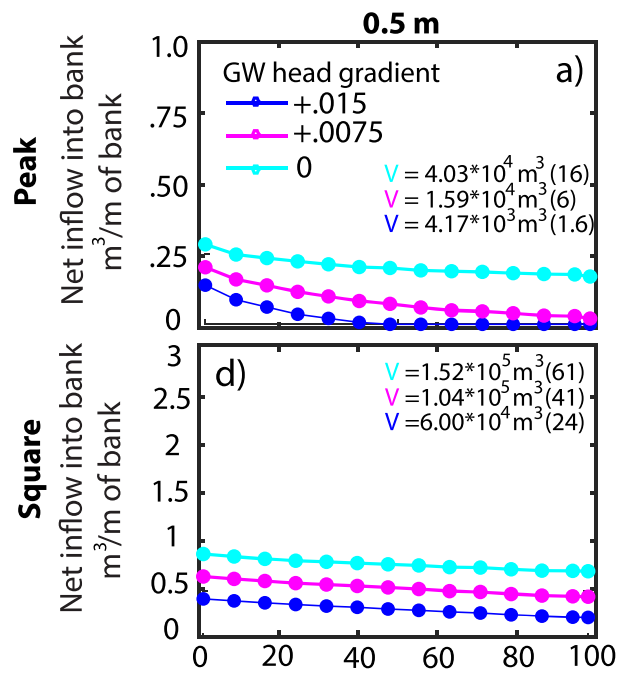

Dam Release Magnitude

$1.0 \mathrm{~m}$
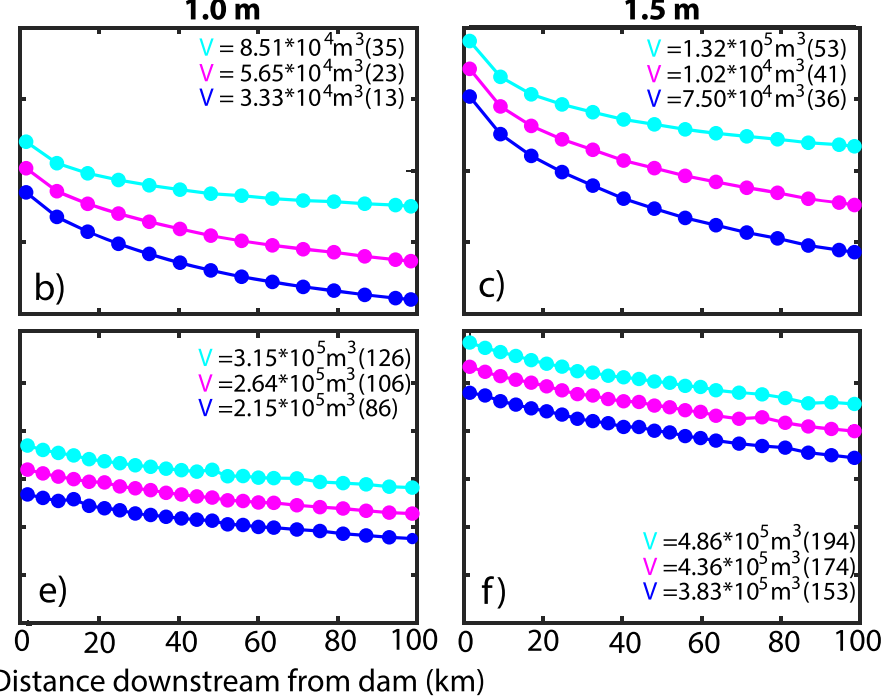

Figure 5. BSE volumes along the 100-km river distance for the different dam release scenarios and groundwater gradients. The three different ambient groundwater gradients were modeled for each scenario-shown in cyan (neutral), magenta $(+0.0075)$, and blue $(+0.015)$. The cumulative volumetric inflow of river water into the banks along the entire 100-km length downstream from the dam is provided in both cubic meters and in parentheses the equivalent number of Olympic swimming pools.

repeating dam releases, this would result in an accumulation of solute in both the saturated and unsaturated zones of the bank.

Comparing the peak and square snapshots, one can see that the square release results in the transport of considerably more river-sourced solute into the riverbank than the peak release. This difference is attributed to the larger amplitude and longer duration of the square flood wave compared to the peak (Figure $4 \mathrm{~g}$ ). In addition to transporting more solute into the bank, the longer wavelength of the square release permits a shorter period for exfiltration (i.e., less time to return to background, preflood wave conditions). This can be seen by comparing the solute distribution at $t=24 \mathrm{hr}$ for the peak and square scenarios. This suggests that under repeating stage fluctuations, square releases would develop a laterally extensive zone of GW-SW mixing in the riverbank more rapidly than peak releases.

\subsection{Longitudinal Results: Neutral and Positive Groundwater Head Gradients}

\subsubsection{BSE Volume Under Neutral and Positive Groundwater Head Gradients}

We quantified net volumetric BSE flux at each model transect, expressed as cubic meters per meter of bank, to illustrate the longitudinal distribution resulting from a dam release moving downstream. For each dam release scenario, the effect of ambient groundwater gradient on volumetric flux is shown for three ambient groundwater conditions (see different colored curves in Figure 5). Each point represents a result from a 2-D transect groundwater flow model simulation and shows that the volumetric fluxes results are dependent on dam release type and size, distance from dam, and ambient groundwater head gradient. Net volumetric flux volumes range from as large as $3 \mathrm{~m}^{3} / \mathrm{m}$ of bank for the largest square release to no net exchange in the case of the smallest peak release under the strongest gaining conditions. Because of the smaller wave height attenuation and longer duration of elevated river stage, square releases cause a much larger volumetric flux than the same size peak release. In fact, the largest volumetric flux for a peak pulse of $\sim 2 \mathrm{~m}^{3} / \mathrm{m}$ of bank was approximately equal to the amount for the smallest square release under neutral conditions.

The ambient groundwater head gradient is an important factor for all dam release scenarios. More strongly gaining groundwater flow conditions resulted in sizeable reductions in volumetric flux. The groundwater head gradient also had a larger effect on reducing volumetric flux with increased longitudinal distance from the dam. To quantify the effect of head gradient, we compared the reduction in volumetric flux under the strongest gaining conditions compared to neutral conditions. The percentage reductions of the volumetric flux for the peak releases were $29 \%, 39 \%$, and $51 \%$ at the dam $(0 \mathrm{~km})$ and $75 \%, 87 \%$, and $100 \%$ at $100 \mathrm{~km}$ downstream, for 1.5, 1.0, and $0.5 \mathrm{~m}$ of release sizes, respectively. For the square releases, the percentage reductions 
were $18 \%, 27 \%$, and $53 \%$ near the dam $(0 \mathrm{~km})$ and $26 \%, 37 \%$, and $69 \%$ at $100 \mathrm{~km}$ downstream for 1.5, 1.0, and $0.5 \mathrm{~m}$ of release sizes.

Another way to evaluate the effects of different dam release scenarios and ambient groundwater conditions is to quantify the cumulative volumetric exchange over the entire river length $(100 \mathrm{~km})$ during the entire flood period $(24 \mathrm{hr}$ ). Cumulative exchange values, $V$, are provided in cubic meters and, for a familiar physical reference, as the equivalent number of Olympic-size swimming pools (Figure 5). The cumulative exchange volumes highlight the effects of shape, size, and ambient groundwater head gradient on the amount of bank storage resulting from these different scenarios. The exchange volume was as small as $4.17 \times 10^{3} \mathrm{~m}^{3}(0.5 \mathrm{~m}$ of peak, head gradient $=0.015)$ or as large as $4.86 \times 10^{5} \mathrm{~m}^{3}(1.5 \mathrm{~m}$ of square, neutral head gradient $)$. Dam release properties and ambient groundwater head gradient conditions can result in a two-order magnitude range in cumulative BSE volume over the 100-km segment downstream from the dam (Figure 5).

\subsubsection{Solute Area Under Neutral and Positive Groundwater Head Gradients}

To test how dam release properties and ambient head gradients control the size of the BSE-zone, we quantified the area in the bank that was infiltrated by the conservative solute tracer from the river defined as $\mathrm{C} / \mathrm{C}_{\text {riv }}>0.25$. Because the duration that the river water resides in the river sediments is also a potentially important factor for biogeochemical reactions involving river-borne solutes, the BSE-zone area is presented as a time series (Figure 6). The dam release properties (shape and size), ambient groundwater head gradient, and proximity from the dam are important factors for both the maximum size and persistence of the BSEzone area (Figure 6). The usefulness of this simple metric is demonstrated by comparing the BSE-zone area for square and peak releases. It is readily apparent that peak releases not only result in much smaller BSEzones but that the BSE-zones are much less persistent, particularly for smaller peak releases under gaining groundwater head gradients (Figure 6).

As stage increases during the rising limb of the dam release flood pulse, the BSE-zone area increases as river water is advected into the bank. For neutral conditions, there is no opposing groundwater head gradient toward the river to limit the advection of solute into the bank, so the size of the BSE-zone grows most rapidly and reaches the largest extents under these conditions (Figure 6). The effect of gaining river conditions (Figure 6) shows that the presence of positive ambient groundwater head gradients results in a smaller BSE-zone area. The modeling results provide insight into the relative influence of ambient groundwater flow conditions on size of the BSE-zone created by the different dam release scenarios. It can be seen that the effect of groundwater head gradient is much more limiting for the peak releases than for the square.

As stage recedes the solute area shrinks as solute that was transported into the bank is advected back into the river. For neutral conditions, the area decreases only a small amount because head gradients that favor return flow are short lived (Figure 6). This is because as the river stage recedes, the groundwater in the bank returns closer to its background state of zero gradient with no ambient groundwater flow to flush solutes back to the river. In contrast, ambient gaining groundwater flow conditions allow for long-term, sustained flushing of the solute from the BSE-zone back into the river, which can be seen in the solute area declining (Figure 6). When considering the solute area over a 24-hr period, it can be seen that with the exception of the $0.5-\mathrm{m}$ peak pulse under the strongly gaining conditions (0.015), both peak and square releases result in an expansion of the BSE-zone in the bank that does not recover to pre-release conditions (Figure 6).

The maximum solute area at each transect along the 100-km longitudinal distance was integrated to obtain a cumulative BSE-zone volume that resulted from the dam release scenarios and groundwater conditions. Under neutral or gaining conditions, there would be no lateral movement of solute between the river and its banks without the transient BSE caused by the stage fluctuations. Thus, the cumulative volumes show how much the size of the BSE-zone was expanded due to the dam releases (Figure 6). Instead of representing a total amount of fluid exchange (Figure 5), the volumes indicate the total size of BSE-zones $\left(\mathrm{C} / \mathrm{C}_{\text {riv }}>0.25\right)$ created along the 100-km distance. The BSE-zone volumes are larger than the fluid flux volumes because the fluid only occupies a fraction of the subsurface area (recall porosity $n=0.3$ ), and additionally, the volume accounts for pore fluid concentrations that are $\mathrm{C} / \mathrm{C}_{\text {riv }}>0.25$. The cumulative BSE-zone volumes range from $1.8 \times 10^{5}$ to $4.6 \times 10^{6} \mathrm{~m}^{3}$ and are also presented as an equivalent volume of Olympic swimming pools. A notable difference is that the BSE-zone volumes span a smaller range than volumetric BSE fluxes. For comparison, the largest and smallest cumulative BSE-zone volumes differ by a factor of 25, while the largest and smallest fluid flux volumes differ by a factor of 100 . 
a)
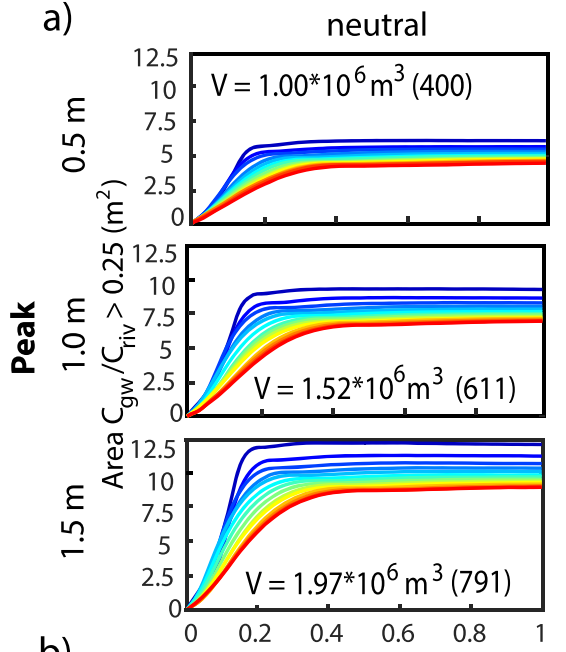

b)

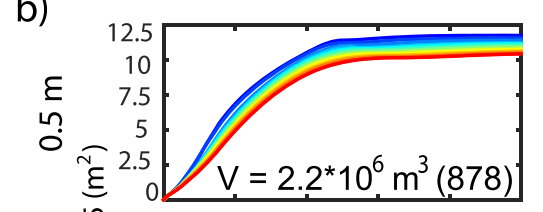

농

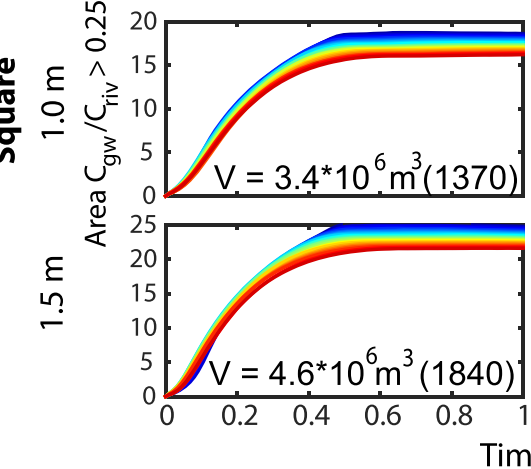

T.

\section{GW head gradient}
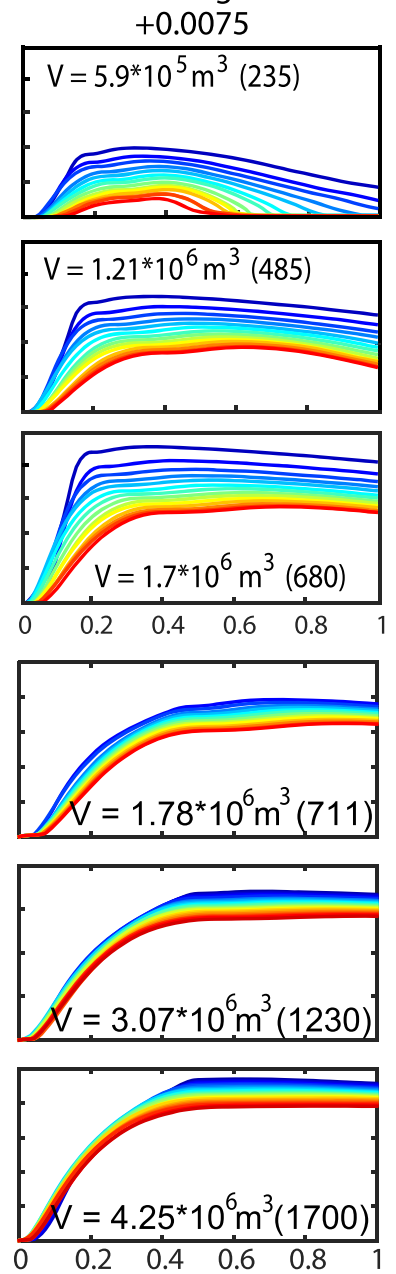
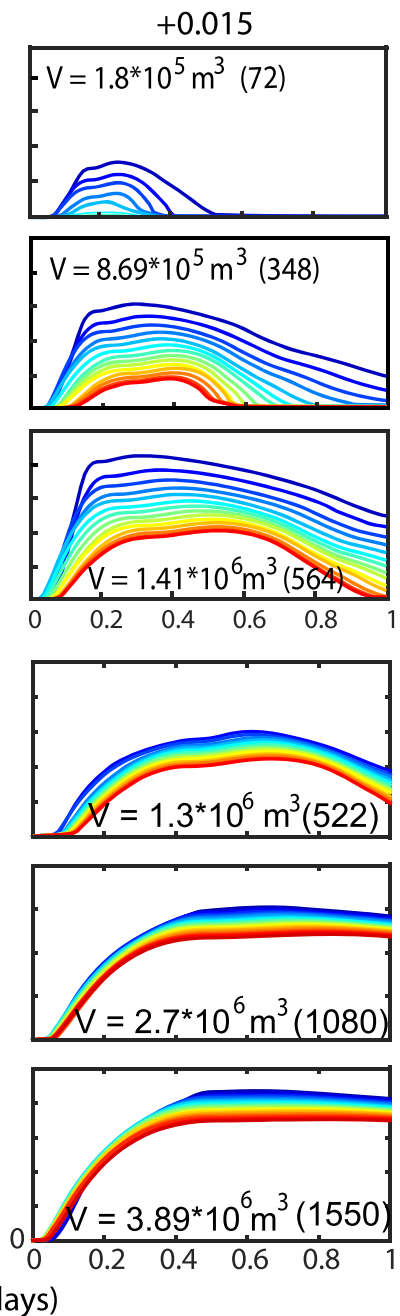

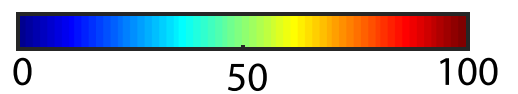

distance downstream from dam $(\mathrm{km})$

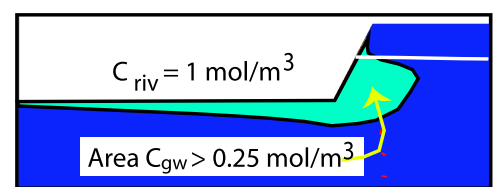

Figure 6. Time series of BSE-zone size during dam releases show area in bank inundated by solute transported from the river into the riverbank. Attenuation of dam release signals as they travel downstream causes differences in timing and size of solute area in the bank with longitudinal distance (colorbar). The cross-sectional areas were used to calculate a total volume of BSE-zone $(V)$ created along the 100-km river length for each scenario. Parenthetical values indicate the volume in equivalent number of Olympic swimming pools. The volume can be thought of as the size of hyporheic zone created by the dam releases.

\subsection{Longitudinal Results: Negative Groundwater Head Gradient}

\subsubsection{BSE Volume Under Negative Groundwater Head Gradient}

We modeled the full suite of dam scenarios under a losing head gradient of -0.0075 to test how the dam releases interact with losing groundwater conditions. For comparison to losses under steady-state conditions, the volumetric flow into the bank under steady losing conditions is shown as a gray line, while the three sizes of dam releases are show as blue $(0.5 \mathrm{~m})$, black $(1 \mathrm{~m})$, and green $(1.5 \mathrm{~m})$. Not surprisingly, the dam releases cause more flow into the bank over $24 \mathrm{hr}$ than steady-state losing conditions. The amount of additional volumetric flux into the bank ranges from as small as a $40 \%$ increase for the $0.5-\mathrm{m}$ peak release to as large as a $600-700 \%$ increase for the $1.5-\mathrm{m}$ square release. Another important feature is the slow decay rate of the volumetric flux. Volumetric fluxes at $100 \mathrm{~km}$ downstream from the dam are still $80-100 \%$ of the value immediately downstream from the dam. 


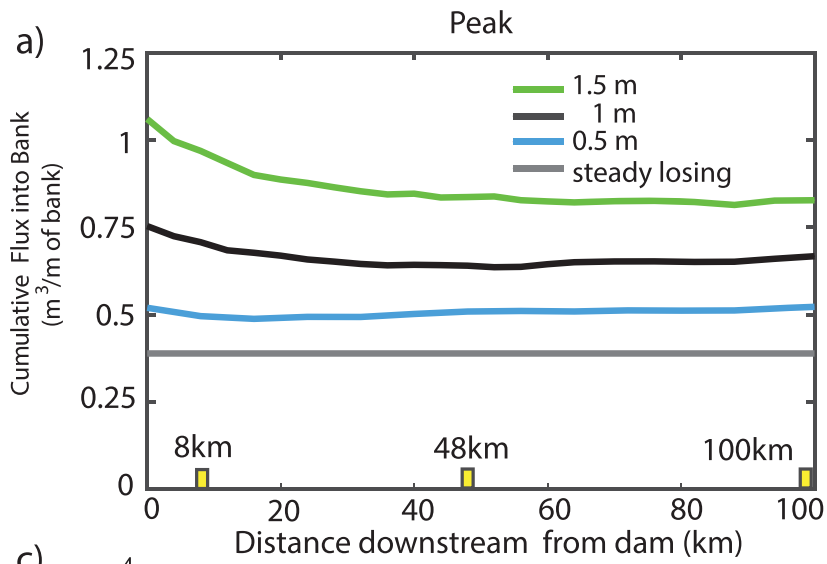

c)
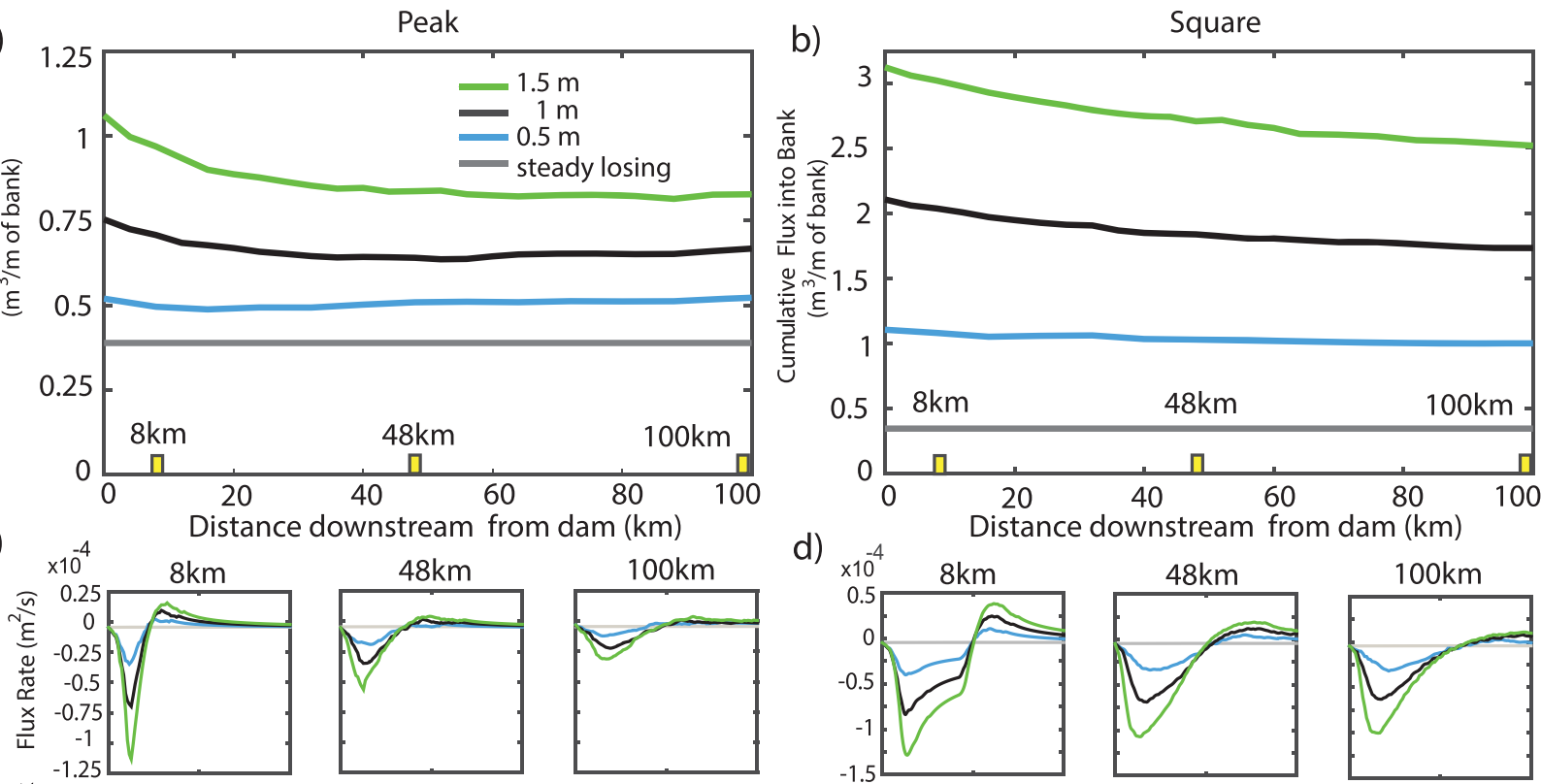

e)

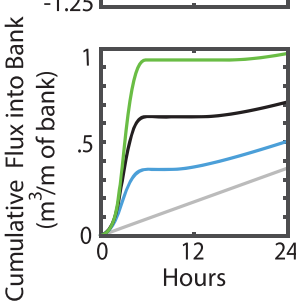

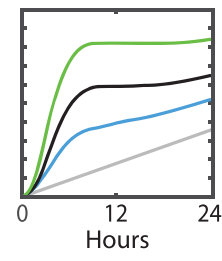

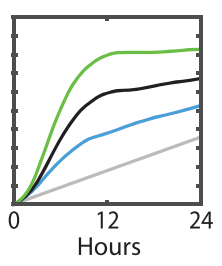

d)

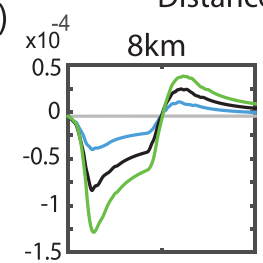

f)

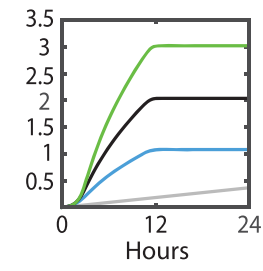

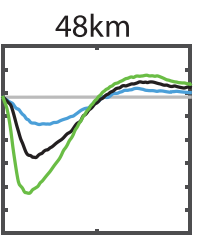

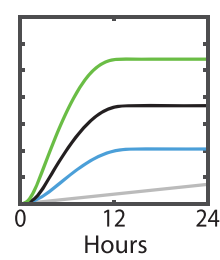

$100 \mathrm{~km}$
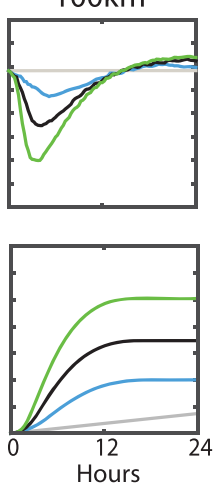

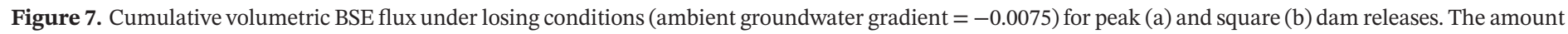

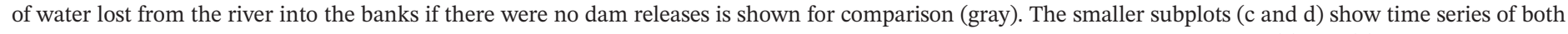

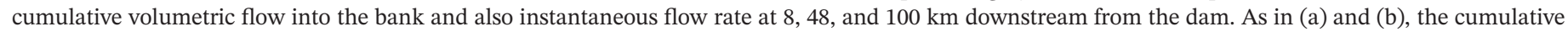
volumetric flow and instantaneous flow rate for the losing condition with no dam releases are shown in gray.

Time series of instantaneous flux across the riverbank interface (Figures 7c and 7d) and cumulative flux into the bank (Figures 7e and 7f) offer additional insight about how the dam releases interact with a bank that has negative head gradients. To show spatial changes in BSE with longitudinal distance from the dam, we present the fluid flux (Figures 7c and 7d) and cumulative flux (Figures 7e and 7f) into the bank at 8, 48, and $100 \mathrm{~km}$ downstream. Fluid flux rate and the cumulative flux into the bank, or the integral of the flux rate, show the temporal response of the inflow of river water into the bank. The sign convention for the flux rate is negative values are flow into the bank while positive values are flow into the river. The fluid flux rates and cumulative flux into the bank show that the dam releases temporarily cause large increases in losses from the river into the bank. This can be seen where the flux rate has large negative values and where the cumulative inflow plots increase much more rapidly than the constant slope of the steady losing condition. A difference between peak and square releases is that the magnitude of losing flux rate decreases much more for peak than square releases. While there is a large reduction in losing flux rate for the peak releases, there is not a large change in the cumulative amount of flow into the bank with distance downstream - seen by the near horizontal shape of the cumulative flux versus distance plots (Figure 7a). The other important difference between the peak and square dam releases is that the square dam releases result in prolonged periods of return flow where some of the water that flowed into the bank during the rising limb of the dam releases flows back into the river during the stage recession. Square releases (Figure 7d) create temporary gaining conditions in what would otherwise be a losing river. The periods of return flow can be seen where the flux rates have positive values and the cumulative flux volumes have a horizontal slope. Our results show that for all sizes of square releases, losing conditions have not resumed after $24 \mathrm{hr}$ since the arrival of the dam release - evidenced by the flat cumulative fluxes for the square scenarios. In contrast, all but the largest (1.5 $\mathrm{m})$ peak release show a return to losing conditions after $24 \mathrm{hr}$. 
a)
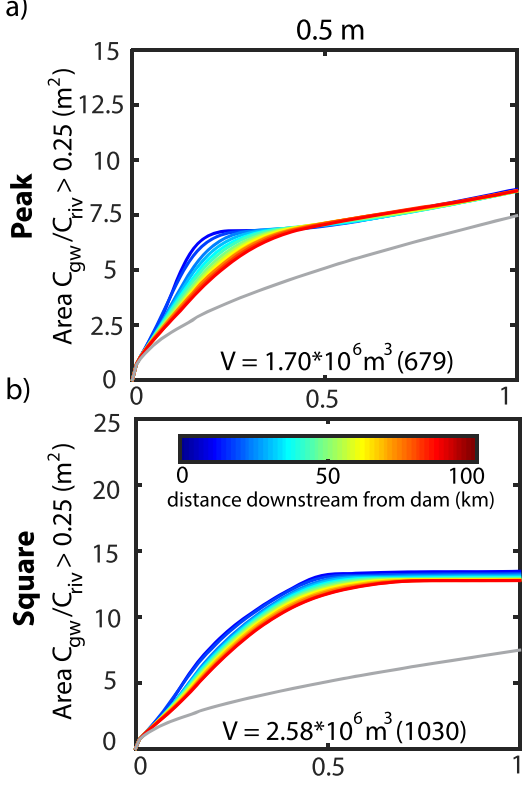

Dam release magnitude $1.0 \mathrm{~m}$
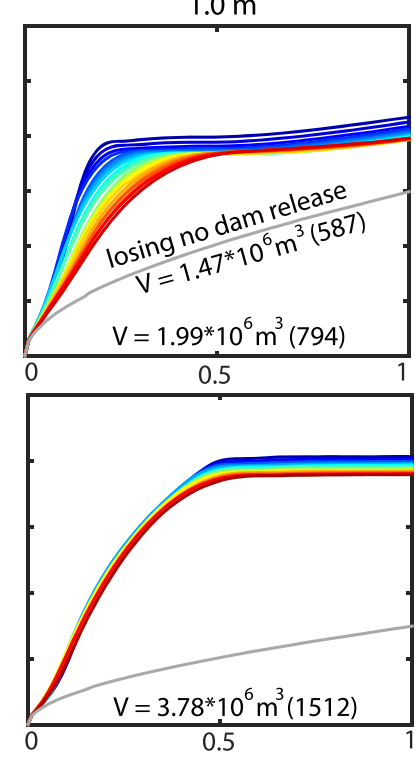

Time since arrival of dam release (days)
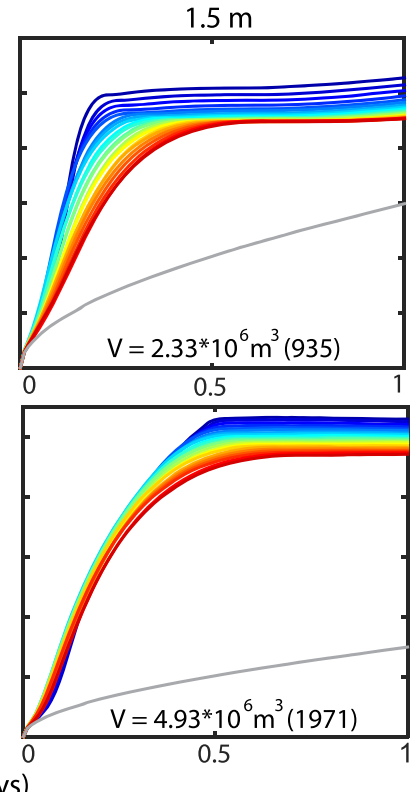

Figure 8. Summary of solute transport from the river into the riverbank for three magnitudes of peak (a) and square (b) dam release types under a losing groundwater gradient $(-0.0075)$. The area that would result from steady losing conditions is shown in gray. The volume bank zone that had $\mathrm{C}>0.25 \mathrm{for}$ the $100-\mathrm{km}$ length of river is listed in cubic meters and Olympic swimming pools.

\subsubsection{Solute Area Under Negative Groundwater Head Gradient}

Time series of solute area in the bank were calculated for the different dam release scenarios under losing groundwater flow conditions. The baseline comparison for these cases is the area of solute that would have formed under steady-state losing conditions with a constant ambient head gradient of -0.0075 . Figure 8 shows the growth in the size of the solute area for each dam release scenario and the steady-state size for comparison in light gray. For all cases, the hydropeaking dam releases create larger BSE-zone areas than the baseline steady losing conditions. Areas for the peak pulses ranged from 1.15 to 1.6 times larger than under no dam releases and 1.74-3.33 times larger for square releases. The difference in cumulative BSE-zone areas between losing and neutral groundwater conditions was largest for the smallest 0.5-m magnitude releases, became smaller as the dam release magnitude increased, and was more significant for peak than for square releases. For comparison, cumulative BSE-zone areas for losing conditions compared to neutral conditions were $70 \%, 30 \%$, and $18 \%$ larger for peak releases and $17 \%, 10 \%$, and $7 \%$ larger for square releases for the release magnitudes of $0.5,1$, and $1.5 \mathrm{~m}$.

\subsection{Longitudinal Results: Varied Channel Roughness and Slope}

Two channel properties that control the propagation of a flood pulse downstream are channel slope and roughness. To test the effects of these two parameters, we routed a 1-m peak release for a channel twice as steep as the one used for this study (Figure 9) and for two different roughness values (Figure 10). A neutral ambient groundwater condition was used for these scenarios.

Steepening the channel slope reduced the amount of attenuation of the flood pulse. The flood pulse height for the $2 \times$ steeper channel was $50 \%(0.21 \mathrm{~m})$ larger at $48 \mathrm{~km}$ downstream and $61 \%(0.19 \mathrm{~m})$ larger at $100 \mathrm{~km}$ downstream. Less attenuation also resulted in the flood pulses having shorter wavelengths. The larger, less attenuated flood pulses due to the steeper channel resulted in larger volumetric inflow into the bank along the 100-km river segment (Figure 9d). In addition to having larger quantities of bank storage inflow, there was less longitudinal decay in the amount of inflow for the steeper channel (Figure 9e). The decay in exchange volume is shown as the fraction of volumetric exchange at a given longitudinal distance compared to the initial amount at the dam $(0 \mathrm{~km})$. At $100 \mathrm{~km}$ from the dam, the exchange volume for the steeper channel is $76 \%$ of the initial amount, while for the original channel slope of 0.0005 , the exchange volume is $65 \%$ of the initial amount. 

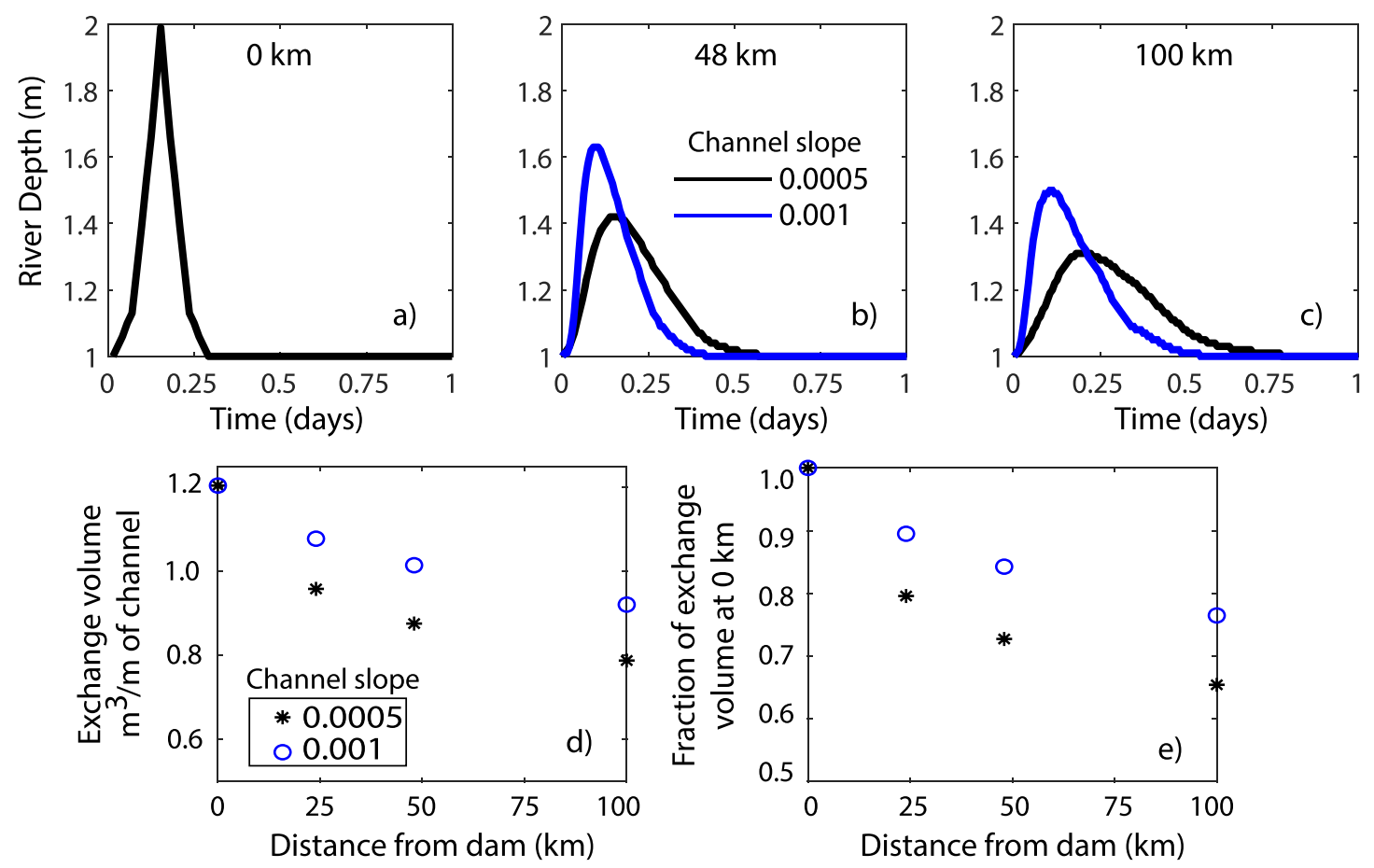

Figure 9. River stage response at 48 (b) and $100 \mathrm{~km}$ (c) downstream due to a 1-m peak release for channel slopes of 0.0005 (black) and 0.001 (blue). Inflow volume per meter of channel (d) and fraction of initial exchange volume (i.e., decay in exchange volume with longitudinal distance) shown in (e).

Increasing the roughness caused greater attenuation of the dam release signal. The resulting flood pulse hydrographs at longitudinal distances of 48 and $100 \mathrm{~km}$ for channel roughness values of $0.025,0.035$, and 0.05 are shown in Figure 10. At $48 \mathrm{~km}$ downstream, an increase in roughness from 0.025 to 0.035 caused
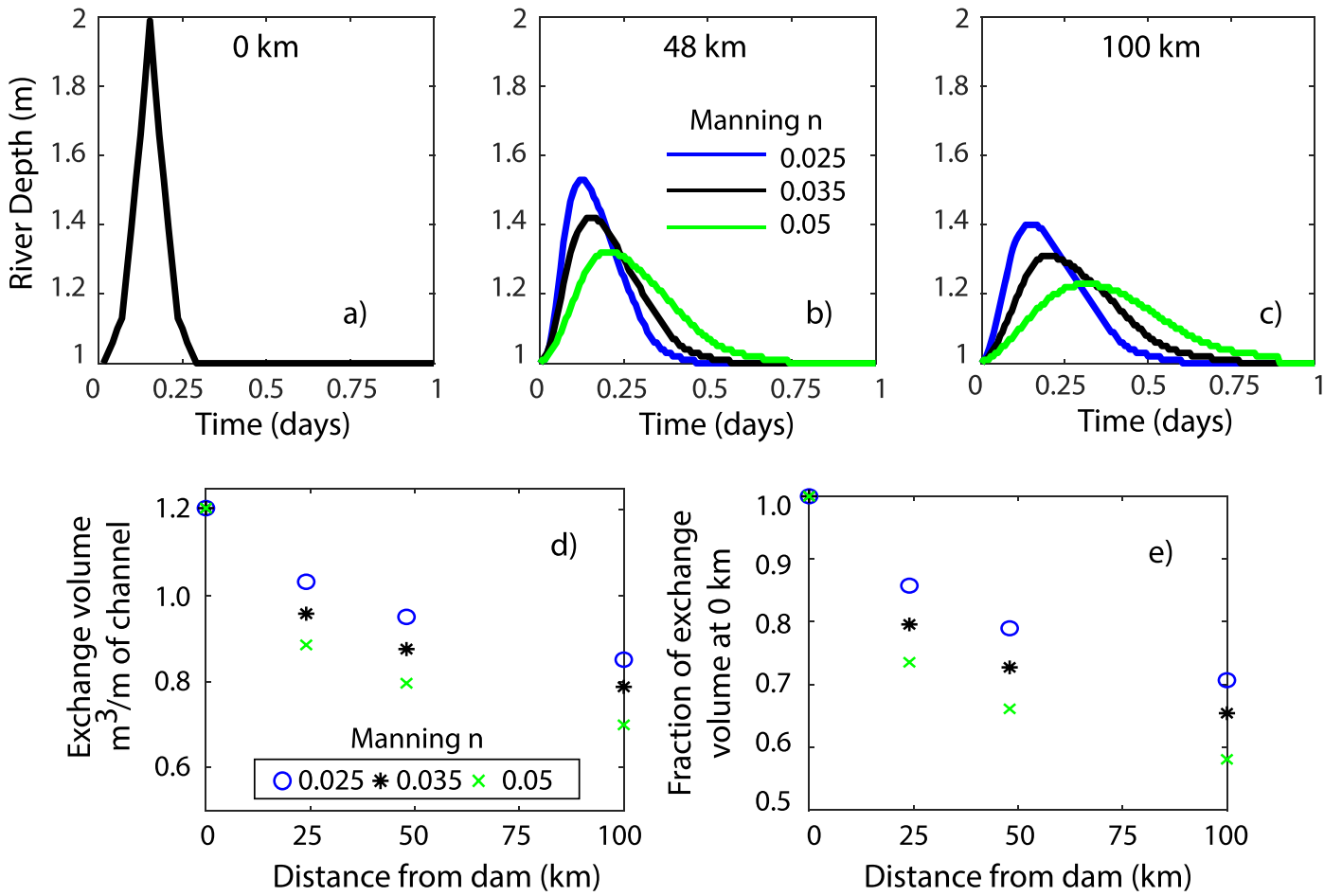

Figure 10. River stage response at 48 (b) and $100 \mathrm{~km}$ (c) downstream due to a 1-m peak release for three roughness values: $0.025,0.035$, and 0.05 . Inflow volume per meter of channel shown in (d) and fraction of initial exchange volume (i.e., decay in exchange volume with longitudinal distance) shown in (e). 

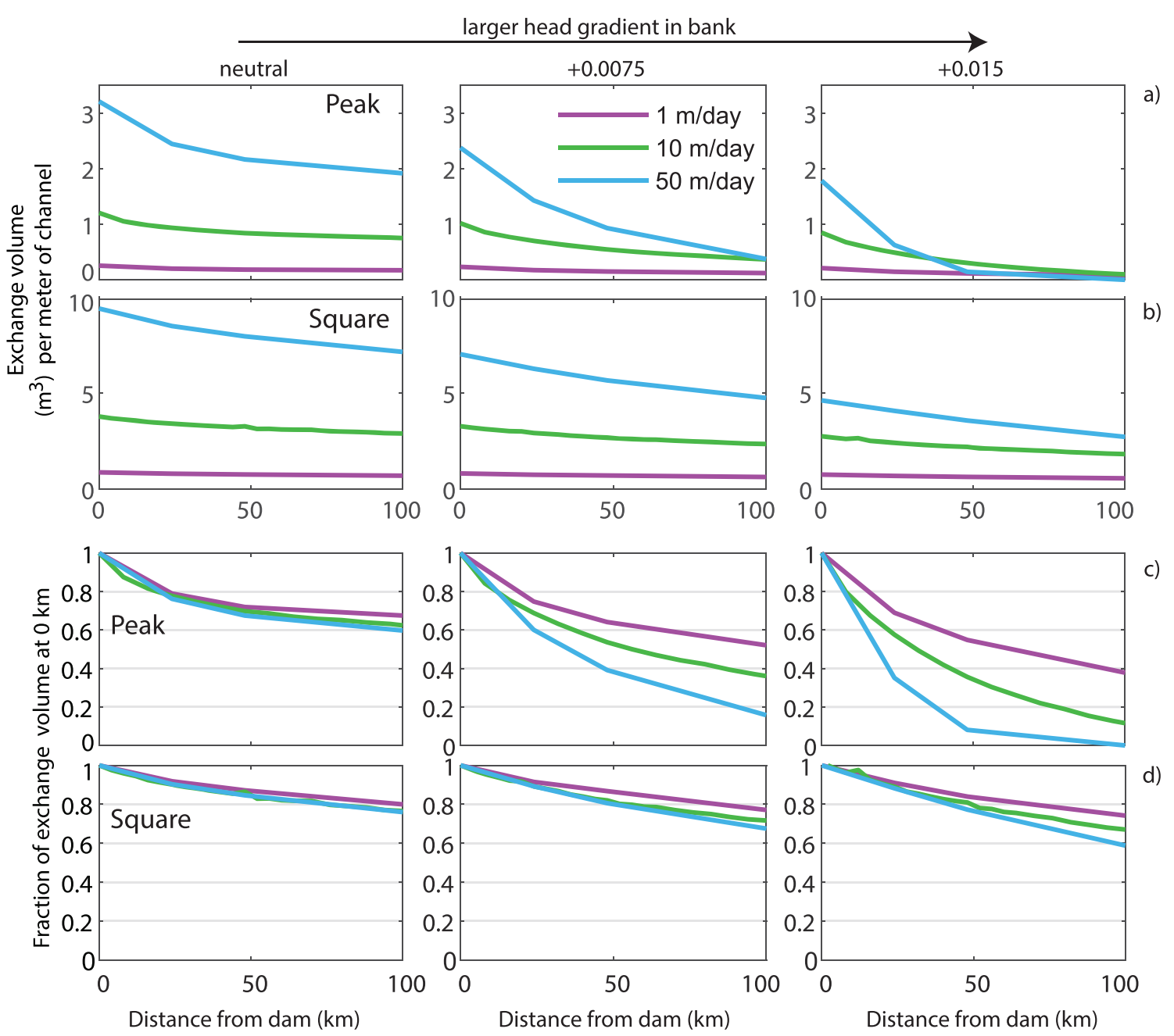

Figure 11. Effect of hydraulic conductivity $K$ on longitudinal volumetric exchange flux for 1-m peak (a) and square (b) releases. Three $K$ values were modeled: 1 (purple), 10 (green), and $50 \mathrm{~m} /$ day (blue). Besides absolute volumetric exchange (cubic meters), the fraction of exchange volume at $0 \mathrm{~km}$ (largest exchange) with longitudinal distance is shown in subplots (c) and (d). The BSE flux as a fraction of initial exchange shows how $K$ affects the longitudinal distribution of exchange flux.

the flood pulse to be reduced from 0.5 to $0.42 \mathrm{~m}$ ( $16 \%$ decrease), and for the highest roughness value of 0.05 , the height is $0.32 \mathrm{~m}$ ( $36 \%$ decrease). The same approximate differences in flood pulse height for the three roughness values are present at $100 \mathrm{~km}$. As was found in the channel slope comparison, the more attenuated flood pulses have less total volumetric exchange (Figure 10d) and display a more rapid decay of exchange with distance (Figure 10e).

\subsection{Longitudinal Results: Varied Hydraulic Conductivity}

To test the effect of hydraulic conductivity on longitudinal BSE exchange, we compared longitudinal volumetric BSE for three $K$ values: 1, 10 (rest of this study), and $50 \mathrm{~m} /$ day. As expected, the results of the varied $K$ simulations for 1-m peak and square releases and three ambient groundwater flow conditions (neutral, 0.0075 , and 0.015 ) showed that increases in $K$ resulted in larger volumetric exchange (Figure 11). The exception was beyond $\sim 40 \mathrm{~km}$ for the peak release with the 0.015 gradient.

The first set of comparisons that can be made are to examine the effect of different hydraulic conductivities and ambient groundwater head gradients at a fixed location. For this comparison exchange volume at the dam $(0 \mathrm{~km})$ is used. At this location the volumetric exchange per meter of channel for $K=1 \mathrm{~m} /$ day ranged from 0.21 to $0.25 \mathrm{~m}^{3}$ for peak and $0.74-0.86 \mathrm{~m}^{3}$ for square, for $K=10 \mathrm{~m} /$ day the range was $0.84-1.2 \mathrm{~m}^{3}$ for peak and 2.74-3.76 $\mathrm{m}^{3}$ for square, and for $K=50 \mathrm{~m} /$ day the range was $1.78-3.2 \mathrm{~m}^{3}$ for peak and $4.6-9.3 \mathrm{~m}^{3}$ 
for square (Figures 11a and 11b). From these values, it can be seen that higher hydraulic conductivity results in larger volumes of exchange and a larger range in exchange volume depending on groundwater conditions. The largest values correspond to neutral conditions, and the smallest values are for the strongly gaining (0.015) ambient head gradient. The percent reductions in inflow due to strongly gaining conditions for $K$ values of 1,10 , and $50 \mathrm{~m} /$ day are, respectively, $16 \% / 30 \% / 44 \%$ for peak and $14 \% / 27 \% / 50 \%$ for square. These results show that higher $K$ increases the limiting effect of gaining groundwater conditions.

The other set of comparisons that can be made are how hydraulic conductivity and ambient groundwater head gradients affect the longitudinal distribution of volumetric BSE. For all three $K$ values the amount of exchange decreases with distance from the dam (Figures 11a and 11b). The effect of $K$ and groundwater conditions is more easily visualized by plotting as fraction of initial exchange volume (Figures 11c and 11d) rather than the absolute volume (Figures 11a and 11b). From Figures 11c and 11d, it can be seen that for all $K$ values volumetric exchange for the peak release decays more rapidly than the square release. Interestingly, under neutral groundwater conditions, $K$ does not appreciably change the decline in exchange volume with distance. Under gaining conditions $K$ does have a significant effect on the amount of decline in exchange volume with distance from the dam. The peak type release appears much more sensitive to changes in hydraulic conductivity than the square release. For example, for the gaining ambient groundwater gradient of 0.0075 , the peak release at $100 \mathrm{~km}$ is $52 \%$ of the initial amount for $K=1 \mathrm{~m}$ /day compared to only $16 \%$ for $K=50 \mathrm{~m} /$ day, while the square release at $100 \mathrm{~km}$ is $77 \%$ of the initial amount when $K=1 \mathrm{~m} /$ day and $67 \%$ of the initial amount when $K=50 \mathrm{~m} /$ day. These results support that as the ambient groundwater gradient becomes more strongly gaining, increases in $K$ will result in more rapid longitudinal decline in inflow volume with distance downstream, and peak releases are more strongly affected by changes in $K$ than square releases.

\section{Discussion}

\subsection{Spatial Patterns of BSE in Dammed Rivers}

The objective of this study was to evaluate how dam release properties and ambient groundwater head gradient, and to a lesser degree aquifer hydraulic conductivity, affect longitudinal patterns of volumetric flux and solute exchange continuously over an extensive river segment during a flood pulse cycle. We found decreasing volumes of fluid exchange and smaller spatial extent of solute infiltration into the bank with increasing distance from the dam. While this finding is not surprising, our results show that even $100 \mathrm{~km}$ downstream and under groundwater conditions that limit flow from the river into the bank (neutral and gaining), there can be volumetric exchanges that are still 52-79\% of the amount near the dam for square releases and from $0 \%$ to $61 \%$ for peak releases. This same comparison can be made for solute area for neutral and gaining conditions (BSE-zone size), which had BSE-zone areas at $100 \mathrm{~km}$ downstream ranging from $74 \%$ to $85 \%$ of the upstream area for square releases and $0.04-73 \%$ for peak releases. The subset of simulations with $K$ values of 1 and $50 \mathrm{~m} /$ day showed similar longitudinal trends in decay of BSE volume with longitudinal distance over the 100-km study reach, suggesting that over this range of $K$ values the same general patterns seen in our full set of analyses $(K=10 \mathrm{~m} /$ day $)$ are present. However, these simulations did suggest that at large $K$ values the limiting effect of ambient gaining groundwater gradients can reduce or eliminate exchange. This idea is supported by Welch et al. (2015) who showed that banks composed of high $K$ sediment with steep water tables can completely limit BSE.

The study results show that larger volumetric exchange leads to the formation of larger BSE-zones-that is, hyporheic zones in the bank. Modeling by Gu et al. (2008) and Gu et al. (2012) showed that BSE induced by flood events increases biogeochemical processing in riverbanks because they create a larger area over which reactions can take place and also increase the residence time of infiltrated river water. Gu et al. (2012) used a multicomponent reactive transport model to explore controls on riparian denitrification. They found that the net hyporheic processing of nitrate following river stage fluctuations was best predicted by the volume of BSE, and that bank storage volume alone could explain $65 \%$ of the nitrate removal following a BSE event.

The time series of solute area (Figure 6) show that ambient groundwater head gradient is an important control on how rapidly solutes are flushed back toward the river from the bank. Our finding that more strongly gaining conditions lead to more rapid flushing and a corresponding reduction of BSE-zone size agrees with Gomez-Velez et al. (2017) who performed a non-dimensionalized analysis of the effect of water table 
gradient, aquifer $K$, and flood pulse signal on residence time distributions in a meander bend. Their study showed that low gradient water tables lead to little flushing of river-sourced solute, longer residence times, and banks that contain much older water. These results agree with our finding that the BSE-zone area for neutral conditions has little reduction in size following a flood pulse. Conversely, their study showed that more strongly gaining conditions lead to more rapid flushing and shorter residence times, which also agrees with our findings.

Field estimates of BSE volumes under hydropeaking conditions are scant because it requires considerable time and resources to install monitoring wells, perform aquifer characterization, and collect the field data to make reliable BSE volume estimates. There is one hydropeaked river that such work was undertaken. At a location $13 \mathrm{~km}$ downstream from a hydropeaking dam that generates daily peak releases of $1.5 \mathrm{~m}$, Sawyer et al. (2009) estimated fluid flux of $1 \mathrm{~m}^{3} / \mathrm{m}$ of bank. This value has been noted numerous times as an example of volumetric flux that can be caused by hydropeaking operations, but at a single location this value lacked longitudinal context. Despite the bank in our model having an order of magnitude lower $K$ than the field location in Sawyer et al. (2009), our results show BSE volumes greater than or equal to their estimate over the entire $100-\mathrm{km}$ river distance for all of the $1.5-\mathrm{m}$ square scenarios and the $1-\mathrm{m}$ square scenario for all but the strongest gaining conditions. The peak scenarios all had much smaller BSE volumes. However, we found that only for the smallest peak release $(0.5 \mathrm{~m})$ was BSE severely limited by gaining groundwater conditions, and all but the $0.5-\mathrm{m}$ peak scenarios exhibited BSE over the entire 100-km distance. We also found that under strongly gaining conditions (ambient head gradient $=+0.015$ ), which is known to limit BSE, hydropeaking can still cause large amounts of BSE well beyond $100 \mathrm{~km}$ downstream -especially for 1 and $1.5 \mathrm{~m}$ of square type releases which had BSE volumes of 0.9 to $2.23 \mathrm{~m}^{3} / \mathrm{m}$ at the $100-\mathrm{km}$ transects. These findings demonstrate the utility of a numerical modeling approach to estimate BSE fluxes compared to the labor and time-intensive field estimates that can only be collected at one or a handful of locations.

A way to interpret the results of volumetric flux under the different ambient groundwater gradients (Figure 5) is to consider their implication for a river that experiences seasonal changes in water table configuration. Consider an alluvial aquifer that shifts from strongly gaining to less strongly gaining or even neutral conditions during a dry period. Our results show that the volume of BSE under the same dam release scenario could increase anywhere from between 5\% and 200\% for square and from 25\% to greater than $600 \%$ for peak releases. Conversely, during wet periods when there is increased recharge to the aquifer, there could be comparably sizeable reductions in BSE. Thus, the importance of BSE in dammed systems could fluctuate seasonally depending on prevailing water table configuration. A similar type of interpretation can be made for a river that has spatially variable water table gradients. Our results show that a reach significantly further downstream, but with a more gradual ambient water table gradient, could have considerably more fluid and solute exchange and larger BSE-zone than an upstream reach.

There are also likely dam-regulated rivers where losing conditions are prevalent seasonally, inter-annually during periods of drought, or spatially within a reach of a river that is locally losing but has neutral or gaining conditions at other locations along the river length. Losing conditions in dammed rivers could be natural or due groundwater pumping (Constantz \& Essaid, 2007; Risley et al., 2010). Our results support that enhanced losses from the river into a bank with losing groundwater conditions extend well beyond $100 \mathrm{~km}$ downstream. Unlike neutral or gaining conditions where the ambient groundwater head gradient limits the movement of surface water into the bank, in a losing river, the bank constantly receives water and solutes from the river even in the absence of stage changes. We found that all sizes of square release result in much larger inputs of water into the bank compared to peak releases and that all sizes of square releases and the largest peak release cause prolonged periods of return flow (gaining conditions) during the falling limb of the dam release. The balance between volumetric inflow during the rising limb and return flow during the falling limb controls the rate at which water will accumulate in the bank and the potential for the water table to be modified over time. Under sustained hydropeaking conditions the enhanced flow into the bank, particularly for the square type release, could cause localized replenishment of groundwater near the channel and over time, a raising of the water table toward more neutral conditions. We expect the timescales over which this would occur to vary widely depending on the dam release shape and size and aquifer hydraulic properties, with peak releases taking much longer than square releases to build up the water table near the riveraquifer boundary. 


\subsection{Lessons for Field Studies of BSE and SW-GW Interaction in Dammed Rivers and Dynamic River Environments}

Most of the research on BSE, and more generally all types of SW-GW interactions, in hydropeaked rivers have been located close to the dams where stage fluctuations are largest (e.g., Arntzen et al., 2006; CasasMulet et al., 2015; Liu et al., 2018; Sawyer et al., 2009; Stegen et al., 2016; Watson et al., 2018). Our findings suggest the need to extend the downstream distance over which SW-GW exchanges are evaluated in hydropeaked rivers, particularly when the type of hydropeaking operation is the square wave type, which results in large volumes of fluid flux and creates large areas of solute exchange with riverbanks well beyond $100 \mathrm{~km}$ downstream from the dam. Our results also support the value of monitoring water table and chemical conditions over extended time periods. This would enable field studies to capture changes in dam release properties (size and shape of dam releases) or seasonal changes in water table gradient that we have shown to have important controls on the amount of fluid and solute exchange in hydropeaked rivers.

An area of active and growing research is understanding how dynamic hydrological environments, such as a hydropeaked river, affect the functioning and types of microbial communities that inhabit river sediments (Graham et al., 2017; Stegen et al., 2016). In its current early stages, this research is aimed at developing processes-based understanding of microbial respiration in river sediments that are subjected to frequent changes in water chemistry due to infiltration/exfiltration caused by river stage fluctuations. Stegen et al. (2016) performed detailed sampling of hyporheic water during daily stage fluctuations created by an upstream hydropeaking dam. They found evidence of elevated microbial metabolism in response to surface water flux into the hyporheic zone. Based on these observations, Stegen et al. (2016) proposed a conceptual model hypothesizing that highly transient hyporheic exchange fluxes (daily timescales) preferentially select microbial communities with traits that are adapted to frequent changes in water chemistry and temperature. A question that our modeling begs is whether downstream changes in BSE result in a longitudinal organization of hyporheic zone microbial community sizes, diversities, and functioning. By applying the modeling approach described here, researchers can estimate how far downstream dam releases could influence fluid and solute exchange by parameterizing their model with representative river properties (width, slope, roughness, and cross-sectional shape), aquifer properties (ambient groundwater conditions and hydraulic conductivity), and dam release hydrographs (ideally from a gauge near the dam).

\subsection{Limitations of This Study and Recommendations for Future Work}

To our knowledge this study is one of the few to integrate longitudinal and transverse analysis of flow and transport processes along a dam-impacted river corridor to analyze BSE. Necessarily, various assumptions in the modeling brought limitations. One limitation was the simplification of the channel morphology to a constant width, slope, and cross-sectional shape. Natural rivers have spatially variable slopes, widths, and depths that influence the discharge-stage relationship. Besides variations in width, depth, and slope, a natural river will have variations in bank morphology, that is, slope. Doble et al. (2012) performed a sensitivity analysis of BSE fluid flux to bank slope. Their results showed that bank slope can result in up to $40 \%$ difference in volumetric exchange for a given stage fluctuation depending on whether the bank slope is gradual (more exchange) or steep (less exchange). In our modeling framework all of these parameters are held uniform, and as a result there is a monotonic decrease in exchange flux and solute area with distance from the dam. Despite these simplifications, the general trend of decreasing BSE due to the attenuation of the daminduced flood wave would be expected as the flood wave from the dam attenuates as it travels downstream. When interpreting our results and when selecting field locations, it should be appreciated that local channel characteristics (slope, width, depth, and bank slope) can affect stage fluctuation and resulting fluid and solute exchange. Finally, advances in computing capabilities now enable sophisticated representations of river-aquifer systems such as done by Zhou et al. (2018) and Shuai et al. (2019) who both modeled hyporheic exchange over a 7-km reach of the Columbia River that experiences daily stage fluctuations from upstream hydropeaking operations. If an investigation is focused on a single river, a tailored approach similar to Zhou et al. (2018) and Shuai et al. (2019) can be taken that incorporates complex river geometry and spatial heterogeneity of hydraulic conductivity.

Another limitation of our modeling framework is the one-way coupling between the river model in HECRAS and the subsurface flow modeling. This approach placed an upper limit on the hydraulic conductivity value that we could use for the alluvial aquifer because we could not use a $K$ value that would result in BSE 
fluxes that would appreciably modify the shape of the flood wave (i.e., Hunt, 1990; Pinder \& Sauer, 1971). BSE volumes and subsurface solute area would be much larger in coarse sand and gravel alluvial aquifers -as demonstrated by comparing the volumetric exchange from the models with $K=50 \mathrm{~m} /$ day compared to the $K=10 \mathrm{~m} /$ day results. However, our modeling of three different $K$ values ranging from $K=1 \mathrm{~m} /$ day up to $50 \mathrm{~m}$ /day show that the resulting longitudinal spatial patterns for the two release types hold across this one and a half order-of-magnitude range in $K$. In the absence of repeating hydropeaking conditions, the duration of return flow from the emptying of the riverbank would increase as $K$ is reduced (Whiting \& Pomeranets, 1997).

Because of the large number of simulations and data generated by our longitudinal approach, this study was limited in the variety of water table configurations that could be considered. Further work could be done expanding the range of water table slopes, particularly assessing BSE dynamics associated with negative (losing) conditions and how dammed rivers in arid and semiarid regions, where losing or even disconnected conditions (e.g., Shanafield et al., 2012) are common, interact with their banks and recharge groundwater. A potential avenue for further research for losing rivers in arid environments would be to test whether BSE can buffer river low flows during dry months, how this buffering behaves longitudinally, and the combined effect of changing climate and presence of dam regulation (e.g., Constantz, 2003; Constantz \& Essaid, 2007; Risley et al., 2010).

Other interesting directions for future work would be to incorporate heat (e.g., Song et al., 2018) or reactive solute (e.g., Gu et al., 2012; Shuai et al., 2017) modeling into the transverse subsurface flow models. This would be another step toward more realistically representing the complex spatiotemporal processes in the riverbanks of hydropeaked rivers. Another important step would be to study the effects of bank storage return flows carrying heat, solute, and fluid back into the river following a dam-induced BSE event and how these return flows influence river conditions. This is an unexplored question that would help determine the ecological importance of BSE in dammed river corridors. These research directions could aid in the management of hydropeaking operations to balance power generation needs with desired ecological outcomes for rivers downstream from hydroelectric dams.

\section{Summary and Conclusions}

This study analyzes the linkage between stage fluctuations caused by hydropeaking dam releases and resulting SW-GW exchanges. We used an integrated longitudinal-transverse framework in which we (1) modeled the transient river stage response over a 100-km distance caused by different types and sizes of dam release and (2) used the resulting river stage data to parameterize a time-varying head boundary condition in 2-D fluid and solute transport models that were used to simulate the resulting SW-GW interaction at various distances from the dam. We quantified both the amount of fluid exchange and the area of the bank that received solute from the river for a suite of different dam release sizes $(0.5,1.0$, and $1.5 \mathrm{~m})$, shapes (peak and square), and ambient groundwater conditions (head gradients of $-0.0075,0.0,0.0075$, and 0.015 ). Additionally, to explore the influence of $K$ on longitudinal exchange, we modeled 1-m peak and square releases for $K$ values of 1,10 , and $50 \mathrm{~m} /$ day.

Our results showed that two common types of dam releases can create BSE-zones well beyond $100 \mathrm{~km}$ downstream of hydroelectric dams. Of the two dam release shapes that we modeled, the square type resulted in substantially larger amounts of BSE fluid and solute flux. However, we found that peak releases that are $1 \mathrm{~m}$ or larger can also result in sizeable quantities of BSE, especially if the groundwater flow is not strongly gaining toward the river. Gaining ambient groundwater gradients reduces volumetric exchange for both types of dam release, has a more limiting effect on smaller amplitude releases, and limits BSE for peak releases more than square releases. Hydraulic conductivity was found to amplify the limiting effect of gaining groundwater conditions. Higher $K$ values cause more rapid decay of exchange volume with longitudinal distance under gaining conditions, and the effect of $K$ is more substantial for peak releases.

Tracking river-sourced solute in the subsurface enabled quantifying how different dam release scenarios (shape and size) and ambient groundwater flow conditions interact to control both the size (area) of the subsurface area that receives solute from the river as a result of a dam release, and also how that area persists after the stage returns to pre-dam release condition. For the simulations with neutral and gaining ambient 
groundwater flow conditions, we found cumulative (over the 100-km distance) volumetric exchange flux with the bank to range from $4 \times 10^{3}$ to $4.9 \times 10^{5} \mathrm{~m}^{3}$ and the size of the BSE-zone volumes created along the 100-km river length ranged from $1.8 \times 10^{5}$ to $4.6 \times 10^{6} \mathrm{~m}^{3}$ depending on the dam signal shape and size. All dam releases scenarios under losing river conditions caused larger volumetric flux into the bank than steady losing conditions and created a larger subsurface area of river-sourced solute than steady-state losing conditions. Time series of fluid flux rates under losing conditions revealed that square releases cause strong and prolonged periods of return flow to the river during river stage recession while peak releases, because of their much smaller exchange volumes, exhibit much shorter and less intense return flow. Our results support that both types of hydropeaking will enhance recharge in losing rivers over long $(>100 \mathrm{~km})$ distances and increase the BSE-zone size compared to steady losing conditions.

If information about the dam release properties, ambient groundwater flow conditions, and hydraulic conductivity are available, the findings here can help predict where hydropower operations will result in relatively active or inactive SW-GW exchanges via BSE. Finally, this study highlights the importance of an integrated longitudinal-transverse flow and transport analysis framework for more fully understanding coupled SW-GW processes in dammed river corridors.

\footnotetext{
Acknowledgments

This research project was supported by the National Science Foundation (EAR1344547 and EAR-1343861) and the Geology Foundation at The University of Texas at Austin. S. B. F. received a student grant from the Geological Society of America. The data produced from the HEC-RAS and Comsol modeling are available in the following Hydroshare data repository: Ferencz_et_al_2019_linked_longitudinal_transverse_river_modeling, HydroShare (http://www.hydroshare. org/resource/ 0471b2df851c400582fbfb971c7357ac) Additionally, the Hydroshare repository also contains a copy of the Comsol model used for this study that can be modified by the user and the dam signal boundary conditions used for the HECRAS modeling.
} Resources Research, 45, W04427. https://doi.org/10.1029/2007WR006526

\section{References}

Arntzen, E. V., Geist, D. R., \& Dresel, P. E. (2006). Effects of fluctuating river flow on groundwater/surface water mixing in the hyporheic zone of a regulated, large cobble bed river. River Research and Applications, 22(8), 937-946.

Bevelhimer, M. S., McManamay, R. A., \& O'Connor, B. (2015). Characterizing sub-daily flow regimes: Implications of hydrologic resolution on ecohydrology studies. River Research and Applications, 31(7), 867-879.

Boano, F., Demaria, A., Revelli, R., \& Ridolfi, L. (2010). Biogeochemical zonation due to intrameander hyporheic flow. Water Resources Research, 46, W07535. https://doi.org/10.1029/2008WR007583

Boutt, D. F., \& Fleming, B. J. (2009). Implications of anthropogenic river stage fluctuations on mass transport in a valley fill aquifer. Water

Brunke, M., \& Gonser, T. (1997). The ecological significance of exchange processes between rivers and groundwater. Freshwater Biology, 37(1), 1-33.

Casas-Mulet, R., Alfredsen, K., Hamududu, B., \& Timalsina, N. P. (2015). The effects of hydropeaking on hyporheic interactions based on field experiments. Hydrological Processes, 29(6), 1370-1384.

Chen, X., \& Chen, X. H. (2003). Stream water infiltration, bank storage, and storage zone changes due to stream-stage fluctuations. Journal of Hydrology, 280(1-4), 246-264.

Constantz, J. (2003). Dams and downstream ground water. Hydrological Processes, 17(17), 3533-3535.

Constantz, J., \& Essaid, H. (2007). Influence of groundwater pumping on streamflow restoration following upstream dam removals. Hydrological Processes, 21(21), 2823-2834.

Cooper, H. H. \& Rorabaugh, M. I. (1963). Ground-water movements and bank storage due to flood stages in surface streams, USGS Water Supply Paper 1536-J, US Government Printing Office, 1963.

Doble, R., Brunner, P., McCallum, J., \& Cook, P. G. (2012). An analysis of river bank slope and unsaturated flow effects on bank storage. Ground Water, 50(1), 77-86.

Findlay, S. (1995), Importance of surface-subsurface exchange in stream ecosystems-The hyporheic zone, Limnology and Oceanography, 40(1), 159-164.

Fread, D.L., Lewis, J.M. (1993). "Selection of $\Delta \mathrm{x}$ and $\Delta \mathrm{t}$ computational steps for four-point implicit nonlinear dynamic routing models", ASCE National Hydraulic Engineering Conference Proceedings, San Francisco, CA.

Gerecht, K. E., Cardenas, M. B., Guswa, A. J., Sawyer, A. H., Nowinski, J. D., \& Swanson, T. E. (2011). Dynamics of hyporheic flow and heat transport across a bed-to-bank continuum in a large regulated river. Water Resources Research, 47, W03524. https://doi.org/10.1029/ 2010WR009794

Gomez-Velez, J. D., Wilson, J. L., Cardenas, M. B., \& Harvey, J. W. (2017). Flow and residence times of dynamic river bank storage and sinuosity-driven hyporheic exchange. Water Resources Research, 53, 8572-8595. https://doi.org/10.1002/2017WR021362

Graham, E. B., Crump, A. R., Resch, C. T., Fansler, S., Arntzen, E., Kennedy, D. W., et al. (2017). Deterministic influences exceed dispersal effects on hydrologically-connected microbiomes. Environmental Microbiology, 19(4), 1552-1567.

Gu, C. H., Anderson, W., \& Maggi, F. (2012). Riparian biogeochemical hot moments induced by stream fluctuations. Water Resources Research, 48, W09546. https://doi.org/10.1029/2011WR011720

Gu, C. H., Hornberger, G. M., Herman, J. S., \& Mills, A. L. (2008). Influence of stream-groundwater interactions in the streambed sediments on $\mathrm{NO}_{3}{ }^{-}$flux to a low-relief coastal stream. Water Resources Research, 44, W44132. https://doi.org/10.1029/2007WR006739

Harvey, J., \& Gooseff, M. (2015). River corridor science: Hydrologic exchange and ecological consequences from bedforms to basins. Water Resources Research, 51, 6893-6922. https://doi.org/10.1002/2015WR017617

Hunt, B. (1990). An approximation for the bank storage effect. Water Resources Research, 26(11), 2769-2775.

Jones, N. E. (2014). The dual nature of hydropeaking rivers: Is ecopeaking possible? River Research and Applications, 30(4), 521-526.

Kennedy, T. A., Muehlbauer, J. D., Yackulic, C. B., Lytle, D. A., Miller, S. W., Dibble, K. L., et al. (2016). Flow management for hydropower extirpates aquatic insects, undermining river food webs. Bioscience, 66(7), 561-575.

Kondolf, G. M., Maloney, L. M., \& Williams, J. G. (1987). Effects of bank storage and well pumping on base flow, Carmel River, Monterey County, California. Journal of Hydrology, 91(3-4), 351-369.

Koussis, A. D., Akylas, E., \& Mazi, K. (2007). Response of sloping unconfined aquifer to stage changes in adjacent stream-II. Applications. Journal of Hydrology, 338(1-2), 73-84.

Larkin, R. G., \& Sharp, J. M. (1992). On the relationship between river basin geomorphology, aquifer hydraulics, and groundwater flow direction in alluvial aquifers. Geological Society of America Bulletin, 104(12), 1608-1620. 
Liang, X. Y., Zhan, H. B., \& Schilling, K. (2018). Spatiotemporal responses of groundwater flow and aquifer-river exchanges to flood events. Water Resources Research, 54, 1513-1532. https://doi.org/10.1002/2017WR022046

Liu, D. S., Zhao, J., Chen, X. B., Li, Y. Y., Weiyan, S. P., \& Feng, M. M. (2018). Dynamic processes of hyporheic exchange and temperature distribution in the riparian zone in response to dam-induced water fluctuations. Geosciences Journal, 22(3), 465-475.

McCallum, J. L., \& Shanafield, M. (2016). Residence times of stream-groundwater exchanges due to transient stream stage fluctuations. Water Resources Research, 52, 2059-2073. https://doi.org/10.1002/2015WR017441

McManamay, R. A., Oigbokie, C. O., Kao, S. C., \& Bevelhimer, M. S. (2016). Classification of US hydropower dams by their modes of operation. River Research and Applications, 32(7), 1450-1468.

Moench, A. F., Sauer, V. B., \& Jennings, M. E. (1974). Modification of routed streamflow by channel loss and base flow. Water Resources Research, 10(5), 963-968.

Newcomb, R. C., \& Brown, S. G. (1961). Evaluation of bank storage along the Columbia River between Richland and China Bar, USGS Water Supply Paper 1539-I, (). Washington: US Government Printing Office.

Pinder, G. F., \& Sauer, S. P. (1971). Numerical simulation of flood wave modification due to bank storage effects. Water Resources Research, 7(1), 63-70, 1971.

Rhodes, K. A., Proffitt, T., Rowley, T., Knappett, P. S. K., Montiel, D., Dimova, N., et al. (2017). The importance of bank storage in supplying baseflow to rivers flowing through compartmentalized, alluvial aquifers. Water Resources Research, 53, 10,539-10,557. https://doi.org/ 10.1002/2017WR021619

Risley, J. C., Constantz, J., Essaid, H., \& Rounds, S. (2010). Effects of upstream dams versus groundwater pumping on stream temperature under varying climate conditions. Water Resources Research, 46, W06517. https://doi.org/10.1029/2009WR008587

Rorabaugh, M. I. (1963). Estimating changes in bank storage and groundwater contribution to streamflow. International Association of Scientific Hydrology. Publication, 63, 432-441.

Rosenberg, D. M., McCully, P., \& Pringle, C. M. (2000). Global-scale environmental effects of hydrological alterations: Introduction. Bioscience, 50(9), 746-751.

Sawyer, A. H., Cardenas, M. B., Bomar, A., \& Mackey, M. (2009). Impact of dam operations on hyporheic exchange in the riparian zone of a regulated river. Hydrological Processes, 23(15), 2129-2137.

Shanafield, M., Cook, P. G., Brunner, P., McCallum, J., \& Simmons, C. T. (2012). Aquifer response to surface water transience in disconnected streams. Water Resources Research, 48, W11510. https://doi.org/10.1029/2012WR012103

Shuai, P., Cardenas, M. B., Knappett, P. S. K., Bennett, P. C., \& Neilson, B. T. (2017). Denitrification in the banks of fluctuating rivers: The effects of river stage amplitude, sediment hydraulic conductivity and dispersivity, and ambient groundwater flow. Water Resources Research, 53, 7951-7967. https://doi.org/10.1002/2017WR020610

Shuai, P., Chen, X. Y., Song, X. H., Hammond, G. E., Zachara, J., Royer, P., et al. (2019). Dam operations and subsurface hydrogeology control dynamics of hydrologic exchange flows in a regulated river reach. Water Resources Research, 55, 2593-2612. https://doi.org/ 10.1029/2018WR024193

Song, X. H., Chen, X. Y., Stegen, J., Hammond, G., Song, H. S., Dai, H., et al. (2018). Drought conditions maximize the impact of highfrequency flow variations on thermal regimes and biogeochemical function in the hyporheic zone. Water Resources Research, 54, 7361-7382. https://doi.org/10.1029/2018WR022586

Squillace, P. J. (1996). Observed and simulated movement of bank-storage water. Ground Water, 34(1), 121-134.

Stegen, J. C., Fredrickson, J. K., Wilkins, M. J., Konopka, A. E., Nelson, W. C., Arntzen, E. V., et al. (2016). Groundwater-surface water mixing shifts ecological assembly processes and stimulates organic carbon turnover. Nature Communications, 7(1). https://doi.org/ $10.1038 /$ ncomms11237

Triska, F. J., Kennedy, V. C., Avanzino, R. J., Zellweger, G. W., \& Bencala, K. E. (1989). Retention and transport of nutrients in a 3rd-order stream in northwestern California: Hyporheic processes. Ecology, 70(6), 1877-1892.

US Army Corps of Engineers, HEC-RAS River Analysis System User Manual (2016). Institute for Water Resources Hydrologic Engineering Center, Davis, CA. vol. 5.0, pp. 1-960.

Watson, J. A., Cardenas, M. B., Ferencz, S. B., Knappett, P. S. K., \& Neilson, B. T. (2018). The effects of floods on the temperature of riparian groundwater. Hydrological Processes, 32(9), 1267-1281.

Welch, C., Cook, P. G., Harrington, G. A., \& Robinson, N. I. (2013). Propagation of solutes and pressure into aquifers following river stage rise. Water Resources Research, 49, 5246-5259. https://doi.org/10.1002/wrcr.20408

Welch, C., Harrington, G. A., \& Cook, P. G. (2015). Influence of groundwater hydraulic gradient on bank storage metrics. Groundwater, 53(5), 782-793

Welch, C., Harrington, G. A., Leblanc, M., Batlle-Aguilar, J., \& Cook, P. G. (2014). Relative rates of solute and pressure propagation into heterogeneous alluvial aquifers following river flow events. Journal of Hydrology, 511, 891-903.

Whiting, P. J., \& Pomeranets, M. (1997). A numerical study of bank storage and its contribution to streamflow. Journal of Hydrology, 202(1-4), 121-136.

Xie, Y. Q., Cook, P. G., Shanafield, M., Simmons, C. T., \& Zheng, C. M. (2016). Uncertainty of natural tracer methods for quantifying river aquifer interaction in a large river. Journal of Hydrology, 535, 135-147.

Yellen, B., \& Boutt, D. F. (2015). Hydropeaking induces losses from a river reach: Observations at multiple spatial scales. Hydrological Processes, 29(15), 3261-3275.

Yim, C. S., \& Mohsen, M. F. N. (1992). Simulation of tidal effects on contaminant transport in porous-media. Ground Water, 30(1), 78-86.

Zhou, T., Bao, J., Huang, M., Hou, Z., Arntzen, E., Song, X., et al. (2018). Riverbed hydrologic exchange dynamics in a large regulated river reach. Water Resources Research, 54, 2715-2730. https://doi.org/10.1002/2017WR020508 